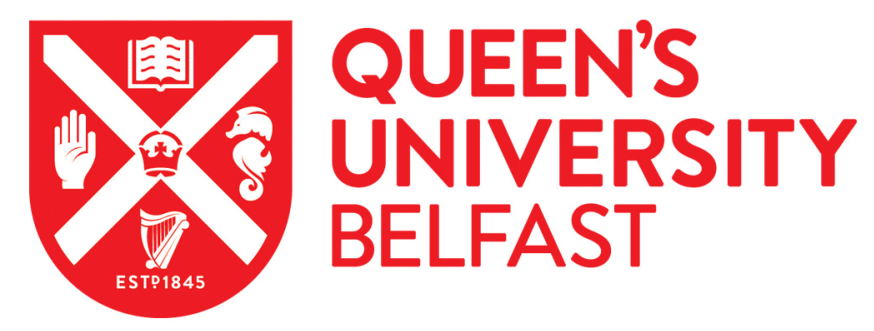

\title{
Determination of the crack resistance curve for intralaminar fiber tensile failure mode in polymer composites under high rate loading
}

Kuhn, P., Catalanotti, G., Xavier, J., Ploeckl, M., \& Koerber, H. (2018). Determination of the crack resistance curve for intralaminar fiber tensile failure mode in polymer composites under high rate loading. Composite Structures, 204, 276-287. https://doi.org/10.1016/j.compstruct.2018.07.039

Published in:

Composite Structures

Document Version:

Peer reviewed version

Queen's University Belfast - Research Portal:

Link to publication record in Queen's University Belfast Research Portal

Publisher rights

Copyright 2018 Elsevier.

This manuscript is distributed under a Creative Commons Attribution-NonCommercial-NoDerivs License

(https://creativecommons.org/licenses/by-nc-nd/4.0/), which permits distribution and reproduction for non-commercial purposes, provided the author and source are cited.

\section{General rights}

Copyright for the publications made accessible via the Queen's University Belfast Research Portal is retained by the author(s) and / or other copyright owners and it is a condition of accessing these publications that users recognise and abide by the legal requirements associated with these rights.

Take down policy

The Research Portal is Queen's institutional repository that provides access to Queen's research output. Every effort has been made to ensure that content in the Research Portal does not infringe any person's rights, or applicable UK laws. If you discover content in the Research Portal that you believe breaches copyright or violates any law, please contact openaccess@qub.ac.uk. 


\section{Accepted Manuscript}

Determination of the crack resistance curve for intralamiar fiber tensile failure mode in polymer composites under high rate loading

P. Kuhn, G. Catalanotti, J. Xavier, M. Ploeckl, H. Koerber

PII:

S0263-8223(18)30807-9

DOI: https://doi.org/10.1016/j.compstruct.2018.07.039

Reference: COST 9957

To appear in:

Composite Structures

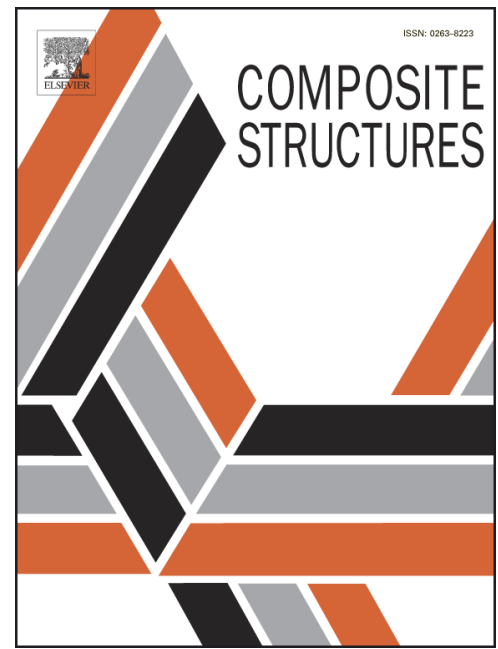

Please cite this article as: Kuhn, P., Catalanotti, G., Xavier, J., Ploeckl, M., Koerber, H., Determination of the crack resistance curve for intralamiar fiber tensile failure mode in polymer composites under high rate loading, Composite Structures (2018), doi: https://doi.org/10.1016/j.compstruct.2018.07.039

This is a PDF file of an unedited manuscript that has been accepted for publication. As a service to our customers we are providing this early version of the manuscript. The manuscript will undergo copyediting, typesetting, and review of the resulting proof before it is published in its final form. Please note that during the production process errors may be discovered which could affect the content, and all legal disclaimers that apply to the journal pertain. 


\title{
Determination of the crack resistance curve for intralamiar fiber tensile failure mode in polymer composites under high rate loading
}

\author{
P. Kuhn ${ }^{\mathrm{a}}$, G. Catalanotti ${ }^{\mathrm{b}}$, J. Xavier ${ }^{\mathrm{c}, \mathrm{d}}$, M. Ploeckl ${ }^{\mathrm{a}}$, H. Koerber ${ }^{\mathrm{a}, *}$ \\ ${ }^{a}$ Technical University of Munich, Department of Mechanical Engineering, Chair for Carbon \\ Composites, Boltzmannstraße 15, 85748 Garching, Germany \\ ${ }^{b}$ School of Mechanical and Aerospace Engineering, Queen's University Belfast, United \\ Kingdom \\ ${ }^{c}$ INEGI, Institute of Science and Innovation in Mechanical and Industrial Engineering, \\ Rua Dr. Roberto Frias 400, 4200-465 Porto, Portugal \\ ${ }^{d}$ CITAB, University of Tras-os-Montes e Alto Douro, UTAD, Quinta de Prados, 5000-801 \\ Vila Real, Portugal
}

\begin{abstract}
This paper presents the determination of the crack resistance curve of the unidirectional carbon-epoxy composite material IM7-8552 for intralaminar fiber tensile failure under dynamic loading. The methodology, proposed by Catalanotti et al. 11 for quasi-static loading conditions, was enhanced to high rate loading in the order of about $60 \mathrm{~s}^{-1}$. Dynamic tests were performed using a split-Hopkinson tension bar, while quasi-static reference tests were conducted on a standard electromechanical testing machine. Double-edge notched tension specimens of different sizes were tested to obtain the size effect law, which in combination with the concepts of the energy release rate is used to measure the entire crack resistance curve for the fiber tensile failure mode. Digital image correlation is applied to further verify the validity of the experiments performed at both static and dynamic loading. The data reduction methodology applied in this paper is suitable for intralaminar fiber failure modes without significant delamination. Sufficient proof is given that quasi-static fracture mechanics theory can also be used for the data reduction of the dynamic tests. It is shown,
\end{abstract}

*Corresponding author. Tel.: +49 8928915042; Fax: +49 8928915097. E-mail address: koerber@lcc.mw.tum.de (H. Koerber)

Preprint submitted to Journal of Composite Structures

July 7, 2018 
that the intralaminar fracture toughness for fiber tensile failure of UD IM7-8552 increases with increasing rate of loading.

Keywords: Fiber-reinforced composites, R-curve, Dynamic fracture, Size effect

\section{Introduction}

Using energy-based damage models ([2, 3, 4, 5, 6, 7, 8, 9, among others) is a promising approach to further enhance the prediction quality of composite simulation models. In these models, the softening law for each failure mode is de-

5 fined by the fracture toughness and related crack resistance curve (R-curve) [10, which has to be measured experimentally.

For the measurement of the intralaminar fracture toughnesses for fiber tensile failure, the compact tension (CT) specimen, originally developed for the fracture toughness characterization in metals [11, 12, is commonly used [13, 14, 15, 16,

10 17, 18, 19]. In contrast to the centre-notched (CN) 20, 21, 22, 23, 24, 25, 26], the double-edge notched (DEN) 27, 28, 29] and the four-point bending (4PB) [27] specimens, the $\mathrm{CT}$ specimen shows a stable crack propagation, which enables the determination of the R-curve. Unfortunately, the $\mathrm{CT}$ specimen has several limitations: i) the tendency of buckling/twisting at the back side (because of the

15 reduced thickness of the specimen [30] or because of the high load that occurs especially when testing high toughened material systems [31]); ii) failure at the back side (because the compressive stress reaches the compressive strength of the material); and iii) failure at the load introduction point.

Overcoming these limitations of the CT specimen, Catalanotti et al. [1] recently measured the fracture toughness for fiber tensile failure using doubleedge notched tension (DENT) specimens and the size effect law. The proposed methodology was also used for the determination of the R-curve at further loading conditions: i) mode I in compression [32] (allowing for the first time the measurement of the full R-curve associated with the propagation of a kink-band);

25 ii) mode II in shear [33]; and iii) testing at extreme environmental conditions 
[34.

To enable the reliable simulation of highly dynamic loading events (e.g. crash, foreign object impact), the strain rate sensitivity of the material properties should be known. Under dynamic loading conditions, no standardized tests exist to measure neither the elastic properties, nor the strength, nor the fracture toughness. Nevertheless, as a result of many studies over the past decades, the strain rate dependency of the stiffness and strength of polymer composites is well known and corresponding review articles were presented by Sierakowski [35] and Jacob et al.[36]. Regarding the dynamic characterization of fracture properties, there is no agreement neither on the rate definition (e.g. as a function of strain rate or crack growth rate) nor on the best suitable experimental and analysis procedure [37.

A methodology to measure the mode I dynamic intralaminar R-curve for compressive fiber failure was recently proposed by Kuhn et al. [38. Using a

40 split-Hopkinson pressure bar (SHPB), which is a widely-used setup for dynamic fracture tests [39], the R-curve for fiber compressive failure was determined for the carbon-epoxy material IM7-8552 by testing double-edge notched compression (DENC) specimens of different sizes at a strain rate of about $100 \mathrm{~s}^{-1}$. The steady-state value of the fracture toughness under dynamic loading was found

${ }_{45}$ to be $63 \%$ higher than the quasi-static reference value. DENC specimens were also tested at an SHPB in a recent study by Leite et al. [40, who tested woven carbon-epoxy specimens at strain rates up to $770 \mathrm{~s}^{-1}$, noticing a significant increase of the compressive fracture toughness with increasing strain rates.

In the presented work, the methodology proposed by Catalanotti et al. [1] to measure the quasi-static R-curve associated with the fiber tensile failure mode is extended to dynamic loading. The R-curves for both quasi-static and high rate loading are obtained by using the relations between the size effect law, initially proposed by Bažant and Planas [41, the energy release rate (ERR) and the R-curve. For the determination of the size effect law, a split-Hopkinson tension bar (SHTB) compatible DENT specimen configuration is used, enabling a symmetric stress state and therefore the desired mode I loading condition 
during the dynamic tests. Following [42], this would not be the case when testing CT specimens under dynamic loading, as the unsymmetrical opening of the CT specimen, caused by inertia effects, would induce mixed mode fracture in the specimen.

\section{Analysis scheme}

According to the peak load condition in fracture mechanics, the energy release rate curve, $G_{I}$, of a so-called positive geometry $\left(G_{I}\right.$ is an increasing function of the crack length $a$ ) is tangent to the R-curve, $R$, at the peak load,

${ }_{65} P_{u}$. This relationship is described by the following system of equations (and visualized in Fig. 3) [41]:

$$
\left\{\begin{array}{c}
G_{I}(\Delta a)=R(\Delta a) \\
\frac{\partial G_{I}(\Delta a)}{\partial \Delta a}=\frac{\partial R(\Delta a)}{\partial \Delta a} .
\end{array}\right.
$$

where $\Delta a$ is the crack increment. Considering a two-dimensional orthotropic body in plane-stress, with the principal material directions $x$ and $y$, and supposing the crack propagates along the $x$-direction, the energy release rate under mode I loading reads 43 :

$$
G_{I}=\frac{1}{\dot{E}} K_{I}^{2}
$$

in which $K_{I}$ is the stress intensity factor and $E$ is the equivalent modulus. According to Suo et al. [43] the latter is defined as:

$$
\dot{E}=\left(s_{11} s_{22} \frac{1+\rho}{2}\right)^{-1 / 2} \lambda^{1 / 4}
$$

with the dimensionless elastic parameters $\lambda$ and $\rho$ defined as [43]:

$$
\begin{gathered}
\lambda=\frac{s_{11}}{s_{22}}, \\
\rho=\frac{2 s_{12}+s_{66}}{2 \sqrt{s_{11} s_{22}}} .
\end{gathered}
$$

$\lambda$ is an indicator of the laminates degree of orthotropy and $s_{i j}$ are the laminate compliances. Supposing that the crack is propagating in a balanced cross-ply 
laminate $\left([0 / 90]_{n s}\right)$,as normally done when measuring the intralaminar fracture toughness of the ply [44], $s_{11}=s_{22}, \lambda=1$ and Eq. 3 reads:

$$
\dot{E}=E\left(\frac{1+\rho}{2}\right)^{-1 / 2}
$$

where $E$ is the laminate Young's modulus $\left(E=E_{x}=E_{y}\right)$.

The stress intensity factor, $K_{I}$, depends on the specimen geometry and can be written for a double edge notched tension (DENT)specimen (Fig. 1) as [43, 45]:

$$
K_{I}=\sigma \sqrt{w} \sqrt{\kappa(\alpha, \rho, \zeta)}
$$

in which $\sigma$ is the remote stress and $w$ is the characteristic size of the specimen (see Fig. 1). $\kappa(\alpha, \rho, \zeta)$ is the dimensionless correction factor for geometry and orthotropy written as a function of the dimensionless parameters $\alpha=a / w$, ${ }_{85} \zeta=\lambda^{-1 / 4} \xi$, and $\xi=w / L$, where $L$ is the free length of the specimen. Placing Eq. 7 in Eq. 2, $G_{I}$ yields:

$$
G_{I}(\Delta a)=\frac{1}{E} w \sigma^{2} \kappa\left(\alpha_{0}+\frac{\Delta a}{w}, \rho, \zeta\right)
$$

where $\alpha_{0}=a_{0} / w$ is the initial yalue of the shape parameter $\alpha$ (see Fig. 1).

To simplify the calculation of the correction factor, the free length of the specimen is scaled with the characteristic size $w(L=5 w$ as shown in Fig. 1). Keeping in mind that the variable $\lambda$ is constant and equal to 1 since the laminate is a balanced cross-ply, the correction factor will only depend on two variables $\alpha$ and $\rho$, since $\zeta$ is now kept constant. Since an analytical solution is not available, $\kappa(\alpha, \rho)$ can be calculated numerically using the Virtual Crack Closure Technique (VCCT) 46]. Following [1, a Finite Element (FE) model of the DENT specimen is built in the commercial software Abaqus [47]. A quarter of the specimen is modeled as shown in Fig. 2 and loaded applying appropriate symmetries and a uniform displacement $u$ at the edges of the free length. For a two dimensional model with four-noded elements, the energy release $G_{I}$ under mode I loading in consideration of the symmetric boundary conditions reads [46]:

$$
G_{I}(a, \rho)=-Y_{m}(a, \rho) u_{n}(a, \rho) / l_{e}
$$




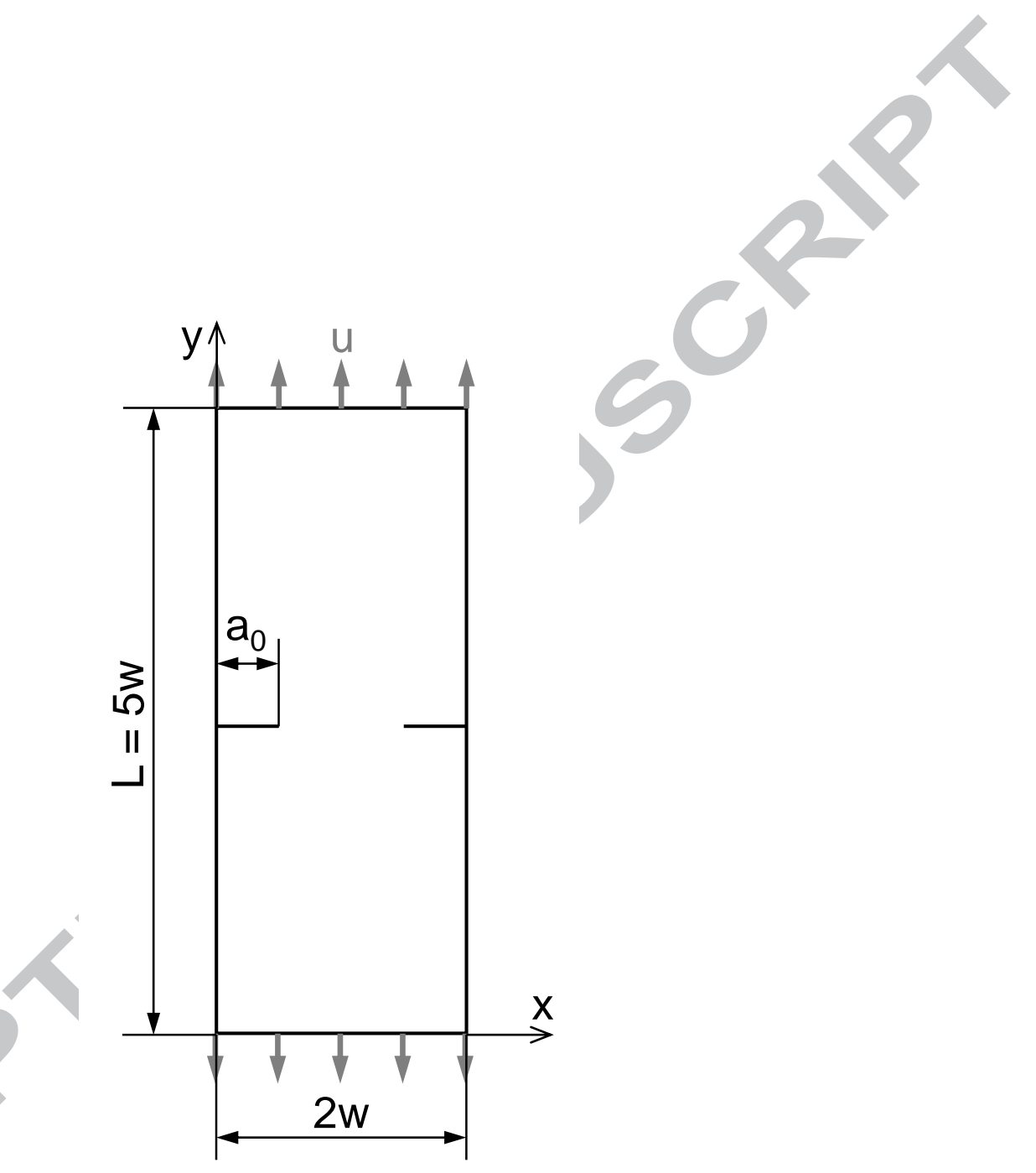

Figure 1: Double edge notched tension (DENT) specimen. 
where $a$ is the crack length, $Y_{m}$ and $u_{n}$ are the load and the displacement in the $\mathrm{y}$-direction of the nodes $m$ and $n$, respectively, and $l_{e}$ is the element size in x-direction (see Fig. 2). Placing Eq. (9) into Eq. (8) and applying $\sigma$, which is also available from the FE simulation, yields $\kappa(\alpha, \rho)$. For a given material data set and specimen design ( $\rho=$ const.), repeating this procedures for several $\alpha$, and fitting the numerical results using a polynomial fitting function enables the calculation of $\kappa(\alpha, \rho)$.

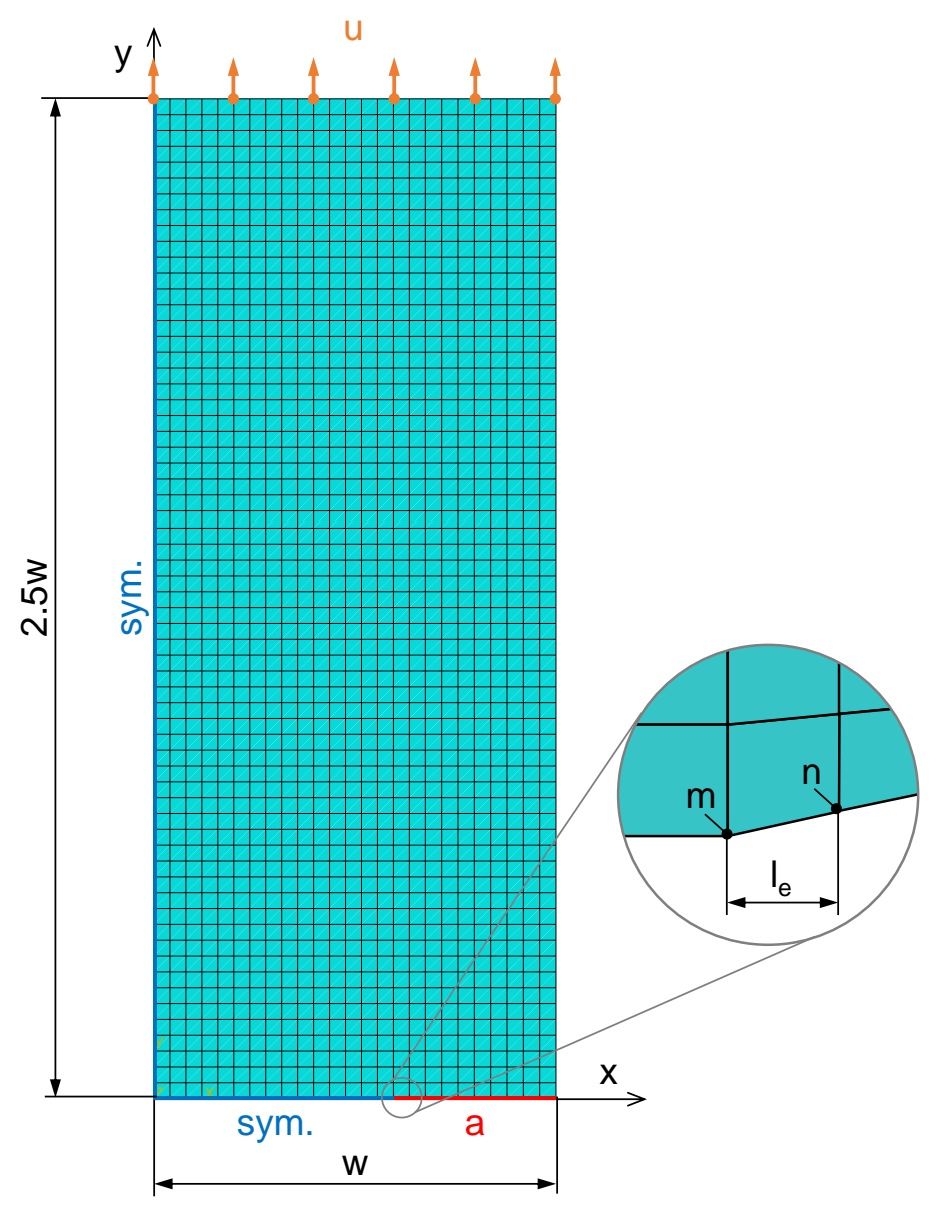

Figure 2: Finite element model used for application of VCCT (after [1]).

While in classic failure theories the strength and consequently the energy 
release rate of a structure is independent of its size, this is not the case for geometrically similar structures made of brittle materials [41. According to Bažant and Planas [41, using this so-called fracture mechanics size effect in combination with the peak load condition of the energy release rate (Eq. 1) is one possible method to measure a crack resistance curve. As illustrated in Fig. 3, the R-curve is the envelope of the energy release rate curves for different specimen sizes, $w_{k}$, at the corresponding peak loads, $P_{u k}$.

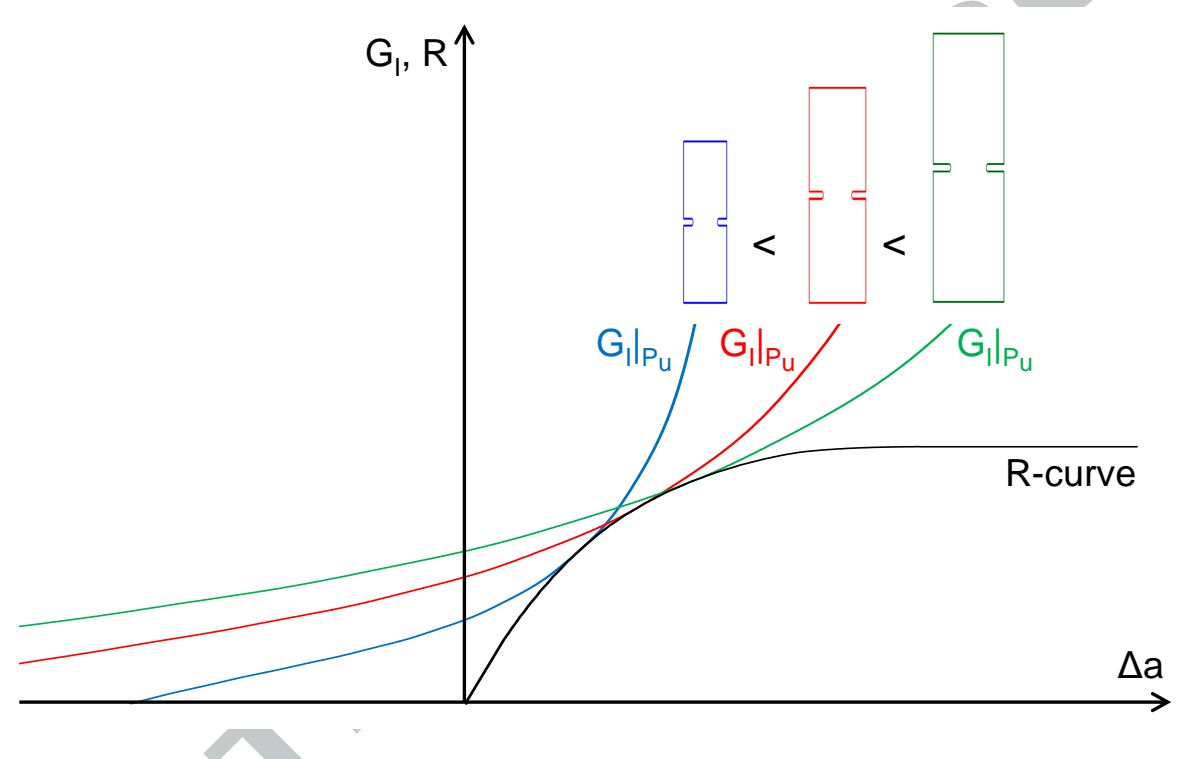

Figure 3: Energy release rate curves $G_{I k}$ for different specimen sizes at respective peak load $P_{u k}$ and R-curve (after [38]).

115 defined as:

$$
\sigma_{u}=P_{u} /(2 w t)
$$

where $t$ is the laminate thickness. Assuming that the size effect law, $\sigma_{u}=\sigma_{u}(w)$, is known, substituting Eq. 8 into the first part of Eq. 1 results in:

$$
\frac{1}{{ }^{\prime}} w \sigma_{u}^{2} \kappa=R(\Delta a)
$$

which holds for every specimen size $w$. In contrast to $G_{I}$, the R-curve is independent of the specimen size $(\partial R / \partial w=0)$ and if geometrically similar specimens 
are tested $\left(\alpha_{0}\right.$ is not a function of $\left.w\right)$ [41, differentiating Eq. 11] with respect to $w$ yields:

$$
\frac{\partial}{\partial w}\left(w \sigma_{u}^{2} \kappa\right)=0
$$

The R-curve of the laminate $R(\Delta a)$ can be calculated by solving Eq. 12 for $w=w(\Delta a)$ and placing this solution into Eq. 11. To get the R-curve of the

${ }_{125} 0^{\circ}$ plies $R_{0}(\Delta a)$, Pinho et al. [13] proposed a rule of mixtures type approach, assuming that the laminate fracture toughness of a cross-ply specimen is the sum of the fiber failure fracture toughness of the $0^{\circ}$ plies and of the matrix failure fracture toughness of the $90^{\circ}$ plies. The corresponding energy balance in case of a crack propagation $\Delta a$ can be written as [32]:

$$
R t \Delta a=R_{0} t_{0} \Delta a+R_{90} t_{90} \Delta a
$$

where $R_{0}$ and $R_{90}$ are the R-curves of the $0^{\circ}$ and $90^{\circ}$ plies, respectively, and $t_{0}$ and $t_{90}$ are the related thicknesses of the plies. Eq. 13 neglects other failure mechanisms such as delamination and splitting and does not account for interactions between the separate failure modes [16. In fiber reinforced polymers the fracture toughness of the fiber failure modes is much higher than for matrix failure modes $\left(R_{0} \gg R_{90}\right)$ and therefore the last term in Eq. 13 can be neglected without a significant loss of accuracy [13, 17. In case of testing a balanced cross-ply specimen, $t_{0}=t_{90}$ and Eq. 13 simplifies to:

$$
R_{0}=2 R
$$

For a balanced cross-ply laminate, the R-curve of the $0^{\circ}$ plies $R_{0}$ is therefore twice the R-curve of the laminate $R$.

\section{Material and experimental procedures}

\subsection{Material and test specimens}

The unidirectional carbon-epoxy prepreg material system HexPly IM7-8552 was used for this work. A panel with a nominal thickness of $1.5 \mathrm{~mm}\left([0 / 90]_{3 s}\right)$ 
was manufactured in a hot press and double edge notched tension (DENT) specimens were extracted from it using a $1.5 \mathrm{~mm}$ diameter milling tool. Slotted steels adapters with outside threads were used to mechanically connect the specimens to the loading apparatuses. All specimens were glued into the adapters applying the structural adhesive 3M Scotchweld DP 490, while proper alignment of the assembled configurations was ensured by using a high accuracy bonding jig.

50 As testing geometrically similar specimens is mandatory for the determination of the size effect law (see section 2) a constant dimension ratio (free length $L$, width, initial crack length $a_{0}$ ) was held for all specimen sizes (Fig. 4). According to [1], the shape of the initial crack tip does not affect the correct determination of the R-curve and was constant (semicircular, $1.5 \mathrm{~mm}$ of diameter) for all specimens. To enable the use of digital image correlation (DIC), the specimens were prepared by applying a random black-on-white speckle pattern.

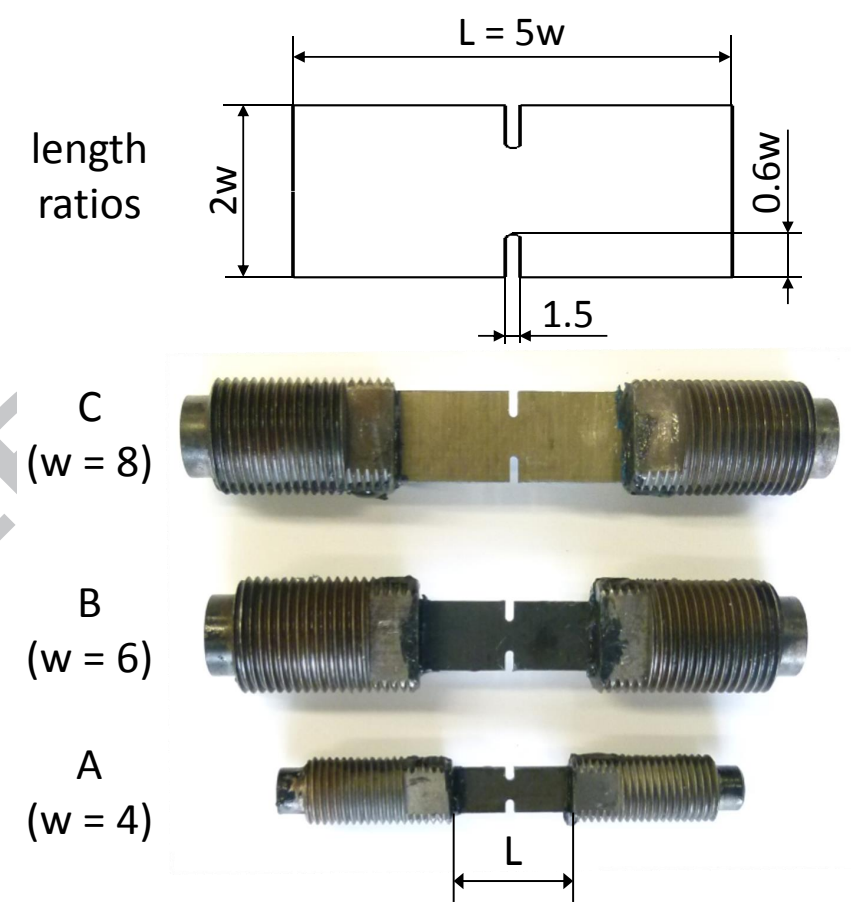

Figure 4: Used specimen geometry (dimensions in $\mathrm{mm}$ ) and assembled specimen configurations of all used sizes. 
The elastic properties of the laminate under quasi-static (QS) and high rate $\left(\mathrm{HR}, \dot{\epsilon}_{s} \approx 60 \mathrm{~s}^{-1}\right)$ conditions are listed in Table 1 Separate tension tests with unnotched specimens were performed to obtain the Young's modulus $E$ of the balanced cross-ply under quasi-static loading. It is well accepted that the longitudinal tensile properties of carbon fiber bundles and carbon fiber composites are strain rate insensitive [48, 49, 50]. Therefore, the QS value of $E$ was also used for the calculations under HR loading conditions. The values for the in-plane shear modulus $G_{x y}$ were taken from [51].

Table 1: Elastic properties of the laminate.

\begin{tabular}{|c|c|c|c|c|}
\hline Strain rate regime & $\begin{array}{l}E \\
{[\mathrm{MPa}]}\end{array}$ & $\begin{array}{l}G_{x y} \\
{[\mathrm{MPa}]}\end{array}$ & $\begin{array}{l}\nu_{x y} \\
{[-]}\end{array}$ & $\begin{array}{l}\rho \\
{[-]}\end{array}$ \\
\hline QS & 95,045 & 5,068 & 0.042 & 9.33 \\
\hline $\mathrm{HR}$ & $95,045(=\mathrm{QS})$ & 6,345 & 0.048 & 7.44 \\
\hline
\end{tabular}

\subsection{Quasi-static experimental setup}

A standard electromechanical testing machine (Hegewald \& Peschke Inspect Table 100), equipped with a $100 \mathrm{kN}$ load cell, was used to conduct the quasistatic (QS) reference tests. The strain rate regime, typically associated with quasi-static loading is between $10^{-5}$ and $10^{-1} s^{-1}[52$ and should be the same for each specimen size to enable a comparison of the results with each other. In the presented work, a cross-head displacement rate of 0.50, 0.75 and $1.00 \mathrm{~mm} / \mathrm{min}$ was chosen for specimen type A, B and C, respectively, resulting in a strain rate of about $2 \times 10^{-4} \mathrm{~s}^{-1}$ (directly determined from the quas-static tests and including the compliance of the load chain) for each specimen size. All tests were carried out under displacement control.

For the DIC measurement of the in plane strain field, a GOM ARAMIS$4 \mathrm{M}$ optical system was used. It consisted of two CCD cameras with a resolution of $1728 \times 2352$ pixel $^{2}$, adjusted to capture a measuring volume of 
$45 \times 35 \times 20 \mathrm{~mm}^{3}$. The frame rate was set to 2 frames per second (fps) in corresponding resolution of $256 \times 128$ pixel $^{2}$ was chosen.

Bars-together (BT) tests for all used SHTB configurations were conducted to verify the accuracy of the bar-strain measurements. Incident- and transmissionbar were connected by a threaded rod for the BT tests. Fig. 6] exemplary shows 205 same settings as for the tests of specimen type $\mathrm{C}$ (see Table 2). The measured pulses show the desired ramp-shaped form. The comparison of the two signals shows, that the wave only slightly changes its shape along the distance between 


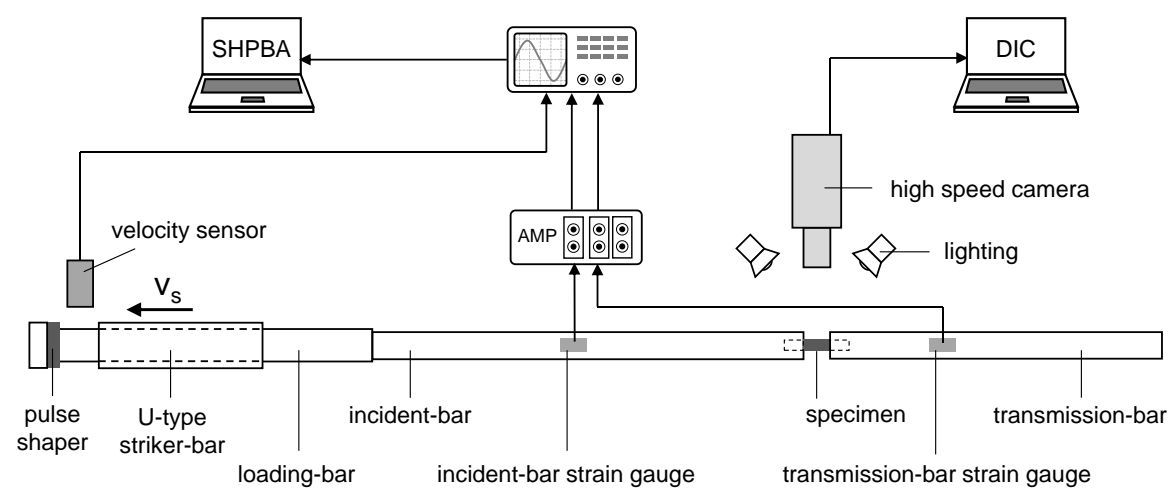

Figure 5: Split-Hopkinson tension bar (SHTB) setup for dynamic tests.

Table 2: Split-Hopkinson tension bar parameters.

\begin{tabular}{lllll}
\hline Specimen type & $w$ & $d_{b}$ & $v_{s}$ \\
& {$[\mathrm{~mm}]$} & {$[\mathrm{mm}]$} & $\begin{array}{l}\text { Pulse shaper type } \\
{[\mathrm{m} / \mathrm{s}]}\end{array}$ & \\
\hline A & 4 & 16 & 7.1 & silicon rubber two-layer \\
B & 6 & 25 & 10.2 & silicon rubber three-layer \\
C & 8 & 25 & 12.2 & silicon rubber three-layer \\
\hline
\end{tabular}

the strain gauges on the incident- and transmission-bar, and dispersion effects can therefore be neglected. The difference in the rear part of the signals is due to the fact that the tensile wave is reflected as a compressive wave at the free end of the transmitted bar and this reflected signal superimposes the original signal. The bar strain gauges themselves were verified by tests with additional strain gauges, mounted on the bars during separate setup tests. A correct 215 determination of the measured bar strains could therefore be expected with the used SHTB system. 


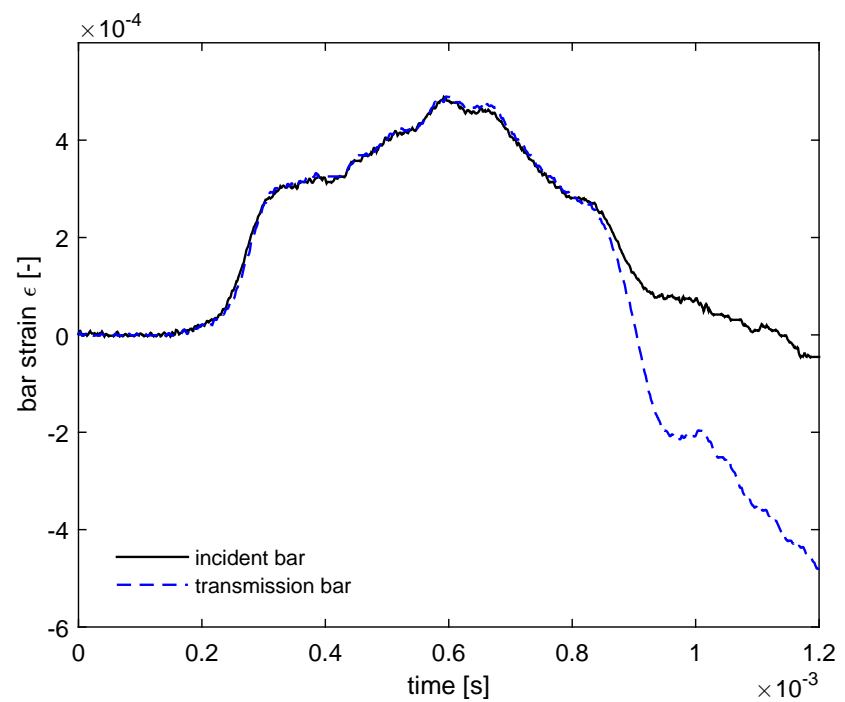

Figure 6: Evaluation of the wave propagation via bars together test $\left(v_{s}=12.2 \mathrm{~m} / \mathrm{s}, d_{b}=25\right.$ $\mathrm{mm})$.

\subsection{Data reduction methods}

\subsubsection{Stress, strain and strain rate}

For the quasi-static tests, the ultimate remote stress, $\sigma_{u}$, was calculated by dividing the peak load, $P_{u}$, measured from the load cell of the testing machine, by the specimen cross-section, $A_{s}$, with $A_{s}=2 w t$ for the used DENT specimen geometry.

In the case of the high rate tests, the axial stress component of the specimen, $\sigma_{s}$, can be calculated with the classic split-Hopkinson pressure bar analysis (SHPBA) [56, [57] by using 1-wave- and 2-wave-analysis:

$$
\begin{gathered}
\sigma_{s 1}=\frac{A_{b}}{A_{s}} E_{b} \varepsilon_{T} \\
\sigma_{s 2}=\frac{A_{b}}{A_{s}} E_{b}\left(\varepsilon_{I}+\varepsilon_{R}\right)
\end{gathered}
$$

where $A_{b}$ is the cross-section of the incident- and transmission-bar and $E_{b}$ is the Young's modulus of the bar material. $\varepsilon_{I}, \varepsilon_{R}, \varepsilon_{T}$ are the measured incident, 
reflected and transmitted bar strain waves, respectively. As both terms (Eq. 15 . Eq. 16) were used to check specimen stress-equilibrium, ultimate remote stress was calculated just from Eq. 15. The transmission wave, $\varepsilon_{T}$ in Eq. 15 has a smooth signal and in contrast to the 2-wave-analysis (Eq. 16), the 1-waveanalysis does not require the shift and superposition of strain waves $\left(\varepsilon_{R}, \varepsilon_{T}\right)$, which is an additional source of error.

The specimen strain $\varepsilon_{s}$ was determined in all tests by using the DIC Software GOM ARAMIS, calculating the nominal engineering strain between two facet points with an initial distance of $L / 2$ along the specimen center line. To ensure comparability, the same procedure was used to obtain the specimen strain in the quasi-static tests. The DIC analysis parameters are given in Table 3 and were chosen accordingly to the resolutions of the camera images.

Table 3: ARAMIS analysis parameters.

\begin{tabular}{|c|c|c|c|c|}
\hline \multirow[t]{2}{*}{ Parameter } & \multirow[t]{2}{*}{ QS } & \multicolumn{3}{|l|}{ HR } \\
\hline & & $\mathrm{A}$ & $\mathrm{B}$ & $\mathrm{C}$ \\
\hline Conversion factor $[\mathrm{mm} /$ pixel $]$ & 0.019 & 0.082 & 0.141 & 0.179 \\
\hline Facet size $\left[\mathrm{pixel}^{2}\right]$ & $17 \times 17$ & \multicolumn{3}{|c|}{$10 \times 10$} \\
\hline Facet step $\left[\mathrm{pixel}^{2}\right]$ & $15 \times 15$ & \multicolumn{3}{|l|}{$5 \times 5$} \\
\hline Computation size $\left[\right.$ facets $\left.^{2}\right]$ & $5 \times 5$ & \multicolumn{3}{|l|}{$5 \times 5$} \\
\hline Strain field resolution [\%] & 0.02 & \multicolumn{3}{|l|}{0.04} \\
\hline
\end{tabular}

The specimen strain rate $\dot{\epsilon}_{s}$ in loading direction is calculated as:

$$
\dot{\epsilon}_{s}(t)=\frac{\varepsilon_{s}(t)-\varepsilon_{s}(t-\Delta t)}{\Delta t}
$$

in which $\Delta t$ is the timestep between two consecutive DIC images.

\subsubsection{Energy terms}

The analysis scheme of this work (see section 2 is based on the quasi-static fracture mechanics theory. Following Jiang and Vecchio [39, quasi-static fracture theory is applicable for dynamic fracture toughness measurements under 
the condition of stress equilibrium. In addition to the classical split-Hopkinson bar equilibrium check (using Eqs.15and 16, the mechanical energy terms of the specimens were calculated and analyzed by using DIC data. This analysis procedure therefore uses the true specimen deformation behaviour, obtained from the optical measurement. On basis of the in-plane strain vector $\left\{\varepsilon_{x}, \varepsilon_{y}, \gamma_{x y}\right\}^{T}$ obtained from DIC, the strain energy of the specimen, $\mathcal{U}$, is the sum of the strain energy at each individual facet point $\mathcal{U}_{j}$, calculated as:

$$
\mathcal{U}=\sum_{j} \mathcal{U}_{j}=\sum_{j} V_{j} \frac{1}{2}\left(E_{x} \varepsilon_{x j}^{2}+E_{y} \varepsilon_{y j}^{2}+G_{x y} \gamma_{x y j}^{2}\right)
$$

in which $\varepsilon_{x j}, \varepsilon_{y j}$ and $\gamma_{x y j}$ are the individual facet's transversal, longitudinal and shearing strain, respectively. $V_{j}$ is the associated volume of the individual facet point, influenced by the thickness of the specimen and the DIC analysis parameters (Table 3). The kinetic energy of the specimen, $\mathcal{K}$, is calculated accordingly on basis of the velocity field from DIC:

$$
\mathcal{K}=\sum_{j} \mathcal{K}_{j}=\sum_{j} \frac{1}{2} D V_{j}\left(v_{x j}^{2}+v_{y j}^{2}\right)
$$

where $v_{x j}$ and $v_{y j}$ are the individual facet's transversal and longitudinal velocity, respectively, and $D$ is the density of the laminate. According to [4], if $\mathcal{K} \ll \mathcal{U}$ and fracture is the only energy-consuming process, quasi-static fracture mechanics theory is applicable.

\section{Experimental results}

\subsection{Specimen deformation and failure}

At least three valid tests are conducted for each specimen type and at each strain rate regime. Fig. 7 shows representatives images of tested specimens. All the specimens failed in a narrow area along the direction of the initial notch. No significant difference on the macroscopic failure surfaces can be seen when comparing the tested QS and HR specimens. More detailed images of the fracture area are shown in Fig. 8. It should be noted that in the used SHTB setup, the already broken specimen halves were subsequently pressed together, making a 
comparison of the microscopic fracture surfaces not reasonable. The reloading is caused by compression waves which travel along the bars after the actual tension test is already finished. Nevertheless, some pulled-out fibers can be seen on the fracture surface images at both strain rate regimes. The detected fiber pull-out contributes an energy portion within the fracture process, and different approaches can be found in literature (e.g. in [1, 19]) to handle with this. Only a small amount of pulled-out fibers is found at both QS and HR loading and the corresponding energy portion is not considered separately in this work.

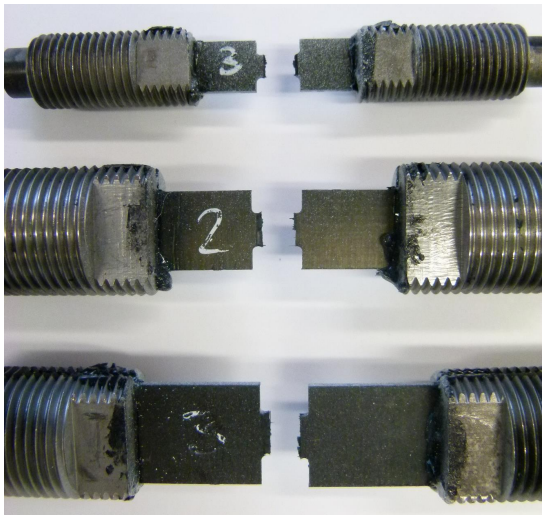

(a) QS

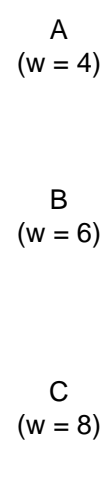

$(w=8)$

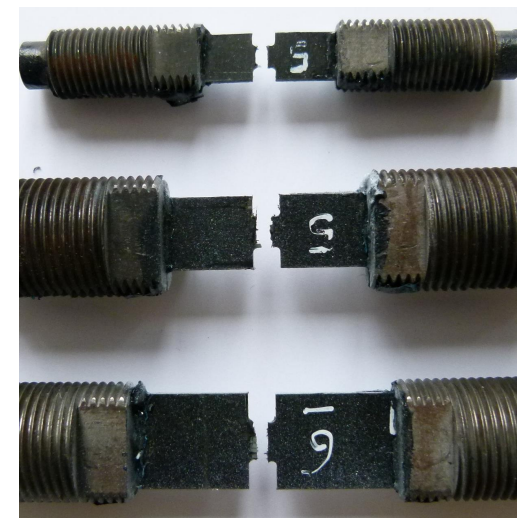

(b) HR

Figure 7: Tested specimens.

Fig. 9 shows the axial and shear strain fields for two specimens of type C. Good agreement can be assumed between the strain distributions at quasi-static and dynamic loading conditions, even though the significantly different image resolutions complicate a detailed comparison. The axis-symmetric axial strain fields (Fig. 9(a)) and the point-symmetric shear strain distributions (Fig. 9(b)) indicate a well aligned loading of the specimens. In particular, the assumption of crack propagation as a result of mode I loading is verified as the shear strain distributions show a strain-less zone at the specimen center. The chosen specimen configuration, consisting of the DENT specimen itself and the slotted endcaps, can therefore be considered suitable either for the QS and HR tests. 


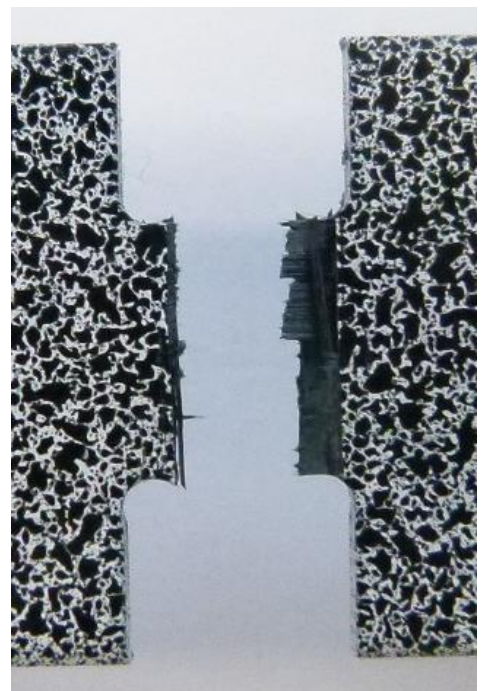

(a) QS

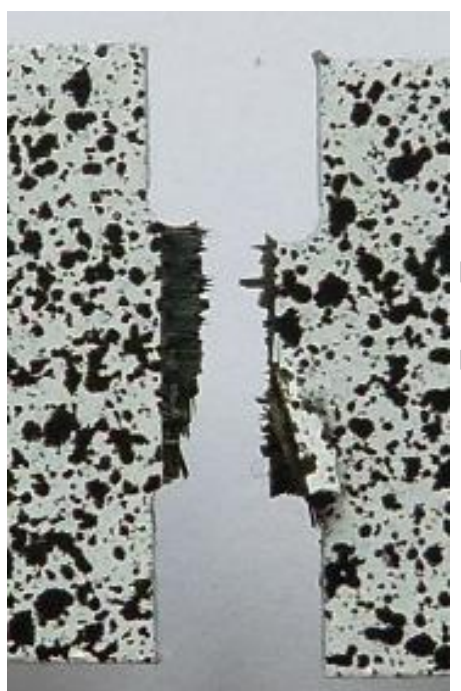

(b) HR

Figure 8: Detailed images of the fracture area (specimen type C).

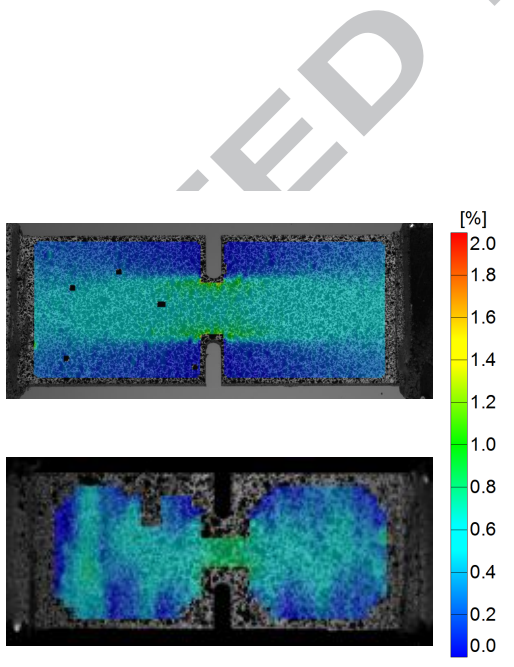

(a) axial strain

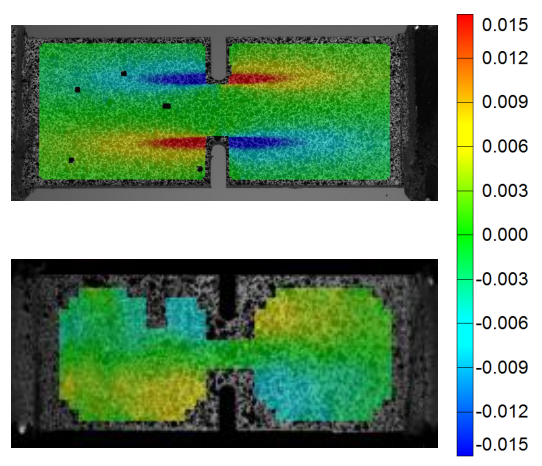

(b) shear strain

Figure 9: axial (a) and shear (b) strain fields at same stress level $(\sigma \approx 310 \mathrm{MPa})$ under QS and HR loading (specimen type C, QS images are rotated $90^{\circ}$ counterclockwise). 


\subsection{Stress-strain behaviour}

290

the different specimen sizes are presented (see Appendix A for all stress-strain curves). The curves are plotted until the point of ultimate failure and nearly linear elastic behaviour can be observed throughout the entire tensile loading duration.

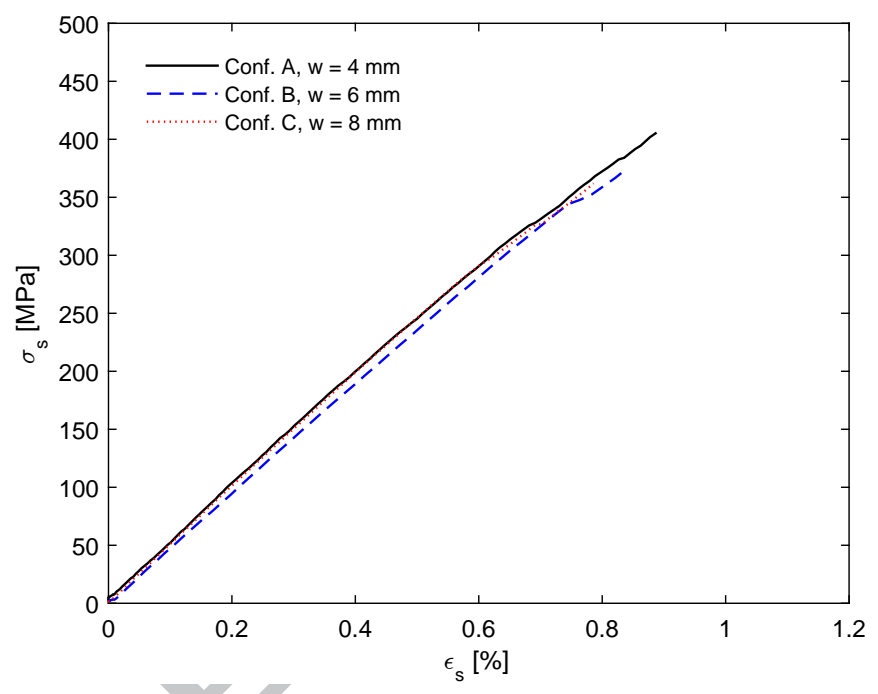

Figure 10: Representative stress-strain curves for QS specimens of all sizes.

295

Fig. 11 shows characteristic strain waves, measured at the incident- and transmission-bar strain gauges during an SHTB test of specimen type $C^{1}$. According to Eq. 15, the transmitted wave is proportional to the axial stress in the specimen. Hence, the sharp drop of $\varepsilon_{T}$ represents the point of the specimen's ultimate failure. At the incident-bar strain gauge, the ramp-shaped tensile pulse $300 \varepsilon_{I}$ is measured, initially. Subsequently, as the incident-wave is partly reflected and partly transmitted at the bar-specimen interface, the reflected wave $\varepsilon_{R}$ is also recorded as a compressive wave by the incident-bar strain gauge. In $\varepsilon_{R}$,

\footnotetext{
${ }^{1}$ The chosen specimen type $\mathrm{C}$ was used for a number of other figures presented in this paper: Fig. 11 can be linked to Figs. 12 13 and 15
} 
ultimate failure of the specimen is apparent as a sharp rise of the strain signal after a plateau-like region. By additionally plotting the entire incident-pulse, stress-time signal indicates that the DENT-specimen is in dynamic stress equilibrium before ultimate failure occurs. This enables the use of the quasi-static fracture theory to obtain the fracture toughness properties [39. It should be noted, that the non-overlapping 2-wave stress is just an approximation due to 330 regime.

Fig. 13 shows representative stress-strain curves for the different specimen 


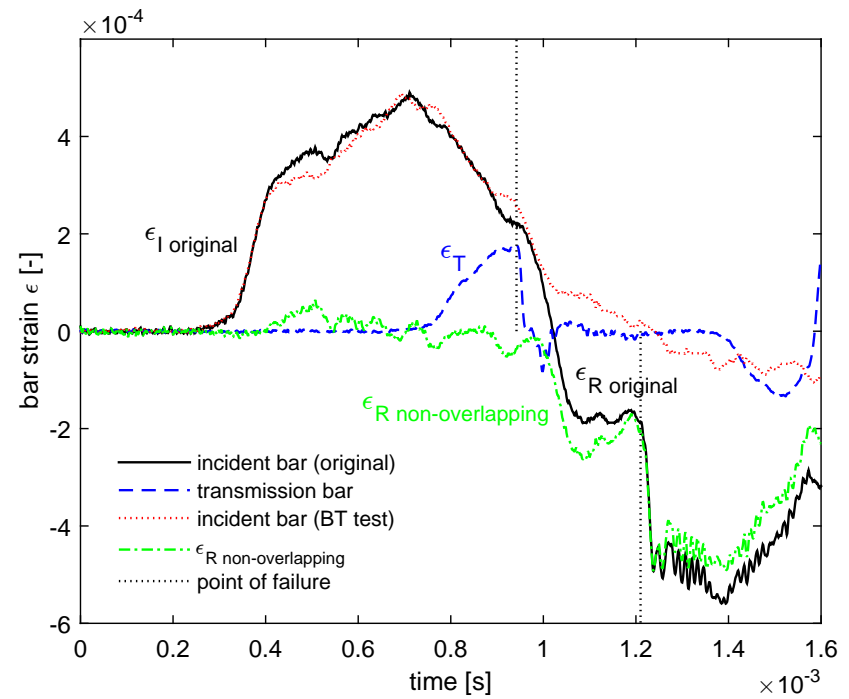

Figure 11: Example of measured bar strain wave groups from SHTB (specimen type C) and $\mathrm{BT}\left(\left(v_{s}=12.2 \mathrm{~m} / \mathrm{s}, d_{b}=25 \mathrm{~mm}\right)\right)$ tests and corrected reflected pulse.

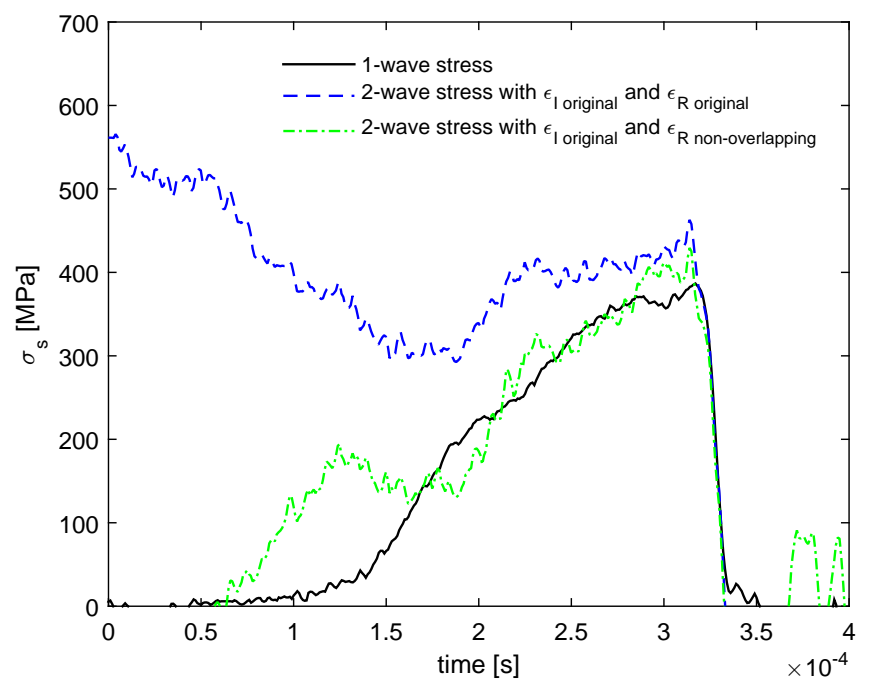

Figure 12: Example of a dynamic stress equilibrium check (specimen type C) with original and corrected bar strain signals. 
sizes, characterized at the SHTB (see Appendix A for all stress-strain curves). The comparison of the stress-strain curves at both investigated strain rate regimes (Figs. 10, 13) indicates that the axial stiffness is strain rate insensitive, which is plausible for carbon fiber laminates, loaded in fiber direction [48, 49, 50]. The ultimate stress $\sigma_{u}$ of the DENT under HR loading is slightly higher than in the QS reference tests. In Fig. 14, $\sigma_{u}$ is plotted versus the characteristic specimen size, $w$. Compared to the QS values, the ultimate stress at $\dot{\epsilon}_{s} \approx 60 \mathrm{~s}^{-1}$ increases by $5 \%, 4 \%$ and $9 \%$ for specimen type A, B and C, respectively. In addition $\sigma_{u}$ is found to decrease with increasing specimen size, which can be explained by the size effect. Table 4 summarizes the results for both investigated strain rate regimes.

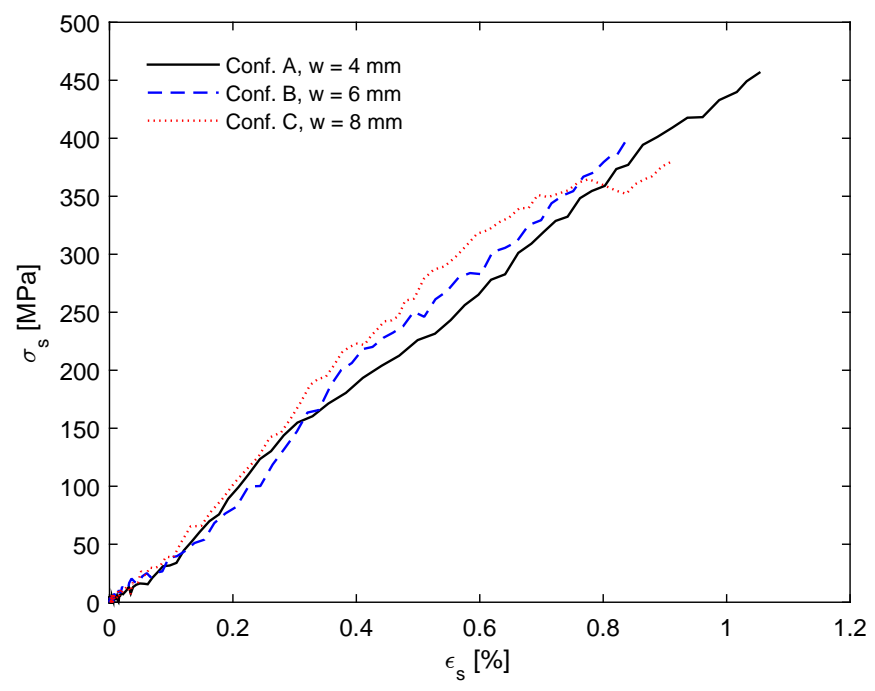

Figure 13: Representative stress-strain curves for HR specimens of all sizes.

Strain rate curves, associated to the QS and HR stress-strain curves of Fig. 10 and Fig. 13 respectively, are presented in Fig. 15 . An axial strain rate of about $2 \times 10^{-4} \mathrm{~s}^{-1}$ is observed for all specimens, that are characterized at the electromechanical testing machine. For the HR tests a nearly constant strain rate in the order of $\dot{\epsilon}_{s} \approx 60 \mathrm{~s}^{-1}$ is achieved for all tested specimen types. Having 


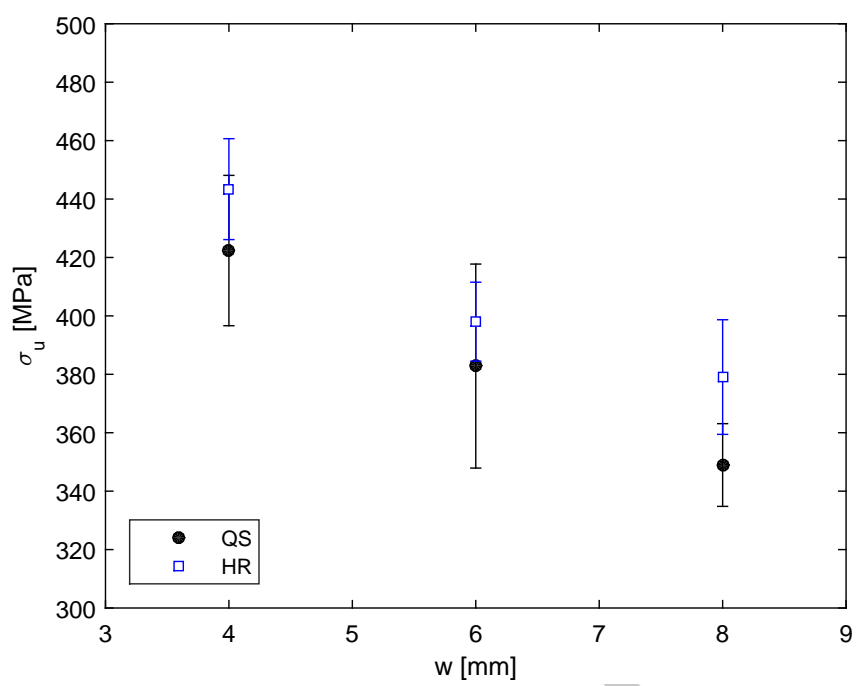

Figure 14: Ultimate stress $\sigma_{u}$ vs. specimen size $w$ for QS and HR loading.

350 between the different specimen types.

Furthermore, a constant strain rate, which is synonymous with a constant relative speed $(\Delta v=0)$ between the specimen's ends, is an additional indicator that the stress equilibrium condition for the SHTB tests is fulfilled. Following

355 Newton's second law $(F=m a)$ with $a=\partial v / \partial t$, it is obvious that a specimen is in force equilibrium if $\Delta v=0$. Therefore, the rising part of the strain-rate curves in Fig. 15 represents the initial acceleration process of the specimens.

\subsection{Energy terms}

Fig. 16 presents strain and kinetic energy curves, calculated according to Eqs. 18 and 19, respectively. During the QS loading of the DENT specimens, the strain energy increases approximately quadratically over time until the point of ultimate failure, which occurs at the last plotted data point (Fig. 16.a)). The QS kinetic energy (Fig. 16(b)) is nearly constant at a very low level during the test. The elevated kinetic energy level at the initial period represents a 
Table 4: Summary of the experimental results

\begin{tabular}{lllll}
\hline & & $\mathrm{A}$ & $\mathrm{B}$ & $\mathrm{C}$ \\
\hline \multirow{2}{*}{$\mathrm{QS}$} & $\mathrm{w}[\mathrm{mm}]$ & 4 & 6 & 8 \\
& $\sigma_{u}[\mathrm{MPa}]$ & 422.4 & 382.8 & 349.0 \\
& $\mathrm{STDV}\left(\sigma_{u}\right)[\mathrm{MPa}]$ & 25.7 & 34.9 & 14.2 \\
& $\mathrm{CV}\left(\sigma_{u}\right)[\%]$ & 6.1 & 9.1 & 4.1 \\
$\mathrm{HR}$ & $\sigma_{u}[\mathrm{MPa}]$ & 443.4 & 398.0 & 379.1 \\
& $\mathrm{STDV}\left(\sigma_{u}\right)[\mathrm{MPa}]$ & 17.3 & 13.5 & 19.6 \\
& $\mathrm{CV}\left(\sigma_{u}\right)[\%]$ & 3.9 & 3.4 & 5.2 \\
\hline
\end{tabular}

chain of the testing machine is completely pre-loaded. The actual loading of the specimen starts at about $30 \mathrm{~s}$, apparent by the rise of the strain-energy curve. As characteristic for quasi-static loading, $\mathcal{K} \ll \mathcal{U}$ during the whole test until the peak load is reached. As expected, the strain energy curve during dynamic testing (Fig. 16.(c)) has a similar shape as under QS loading. However, the kinetic energy under HR loading is found to increase over time. During an SHTB test, both bar-specimen interfaces are in motion, which is in contrast to a test with an electromechanical testing machine, where one specimen interface is approximately at rest while the other is loaded by the cross-head displacement. The specimen is therefore deformed by the relative displacement between the two interfaces during SHTB testing and the kinetic energy in the specimen therefore comes partially from the superposed rigid body movement of the DENT-specimen. In Fig. 16(d) the kinetic energy associated to the rigid body movement $\mathcal{K}_{R B}$ is plotted, additionally. The calculation is based on the assumption that the displacement of the DIC data points, which are closest to the interface to the transmission-bar provide a good approximation of the rigid body motion of the specimen. The curves in Fig. 16.(d) show that about half of the kinetic energy under HR loading can be attributed to the rigid body movement of the DENT specimen. For all HR tests, the ratio of $\mathcal{U} / \mathcal{K}$ at ultimate 


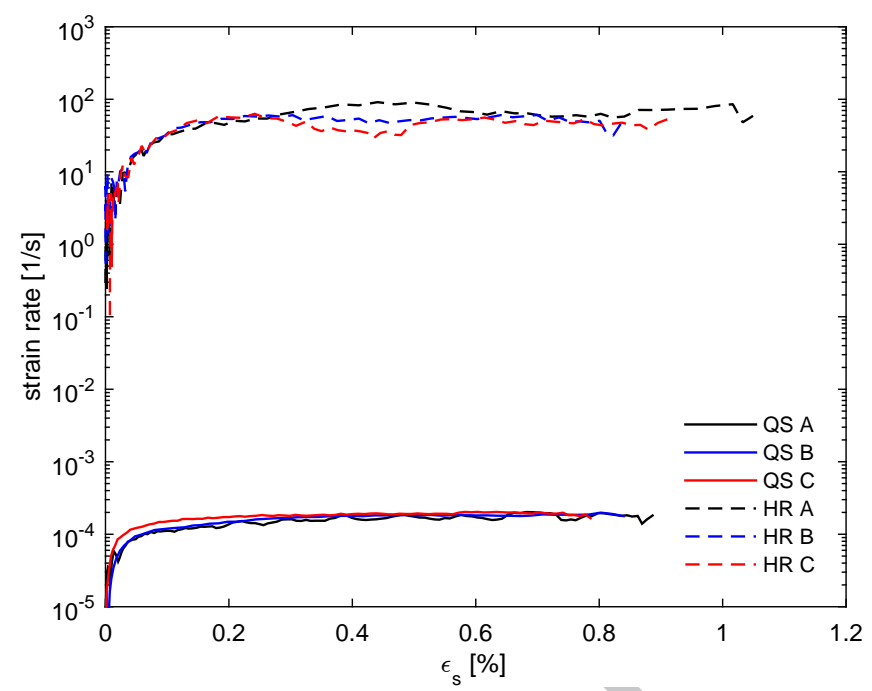

Figure 15: Representative strain rate curves for QS and HR loaded specimens.

\section{Obtaining the Fracture Toughness Properties}

All parameters of the analysis scheme except for the size effect law can be calculated on basis of the material and specimen geometry data, described in section 3). Fig. 17 presents the plot of the dimensionless correction function $\kappa$ over the shape parameter $\alpha=a / w$ for the QS and HR material data sets. Both curves are only slightly different, due to the fact that the Young's modulus $E$ is strain rate independent (see Table 1).

For the determination of the size effect law $\sigma_{u}=\sigma_{u}(w)$, three different fitting approaches are recommended by Bažant and Planas [1]: (i) linear regression I, (ii) linear regression II and (iii) bilogarithmic regression. The corresponding 


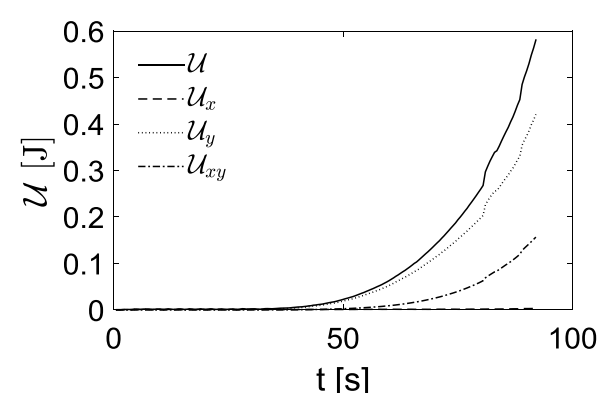

(a) QS strain energy

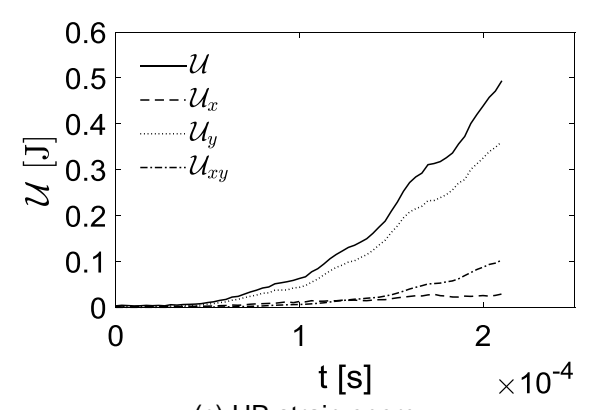

(c) HR strain energy

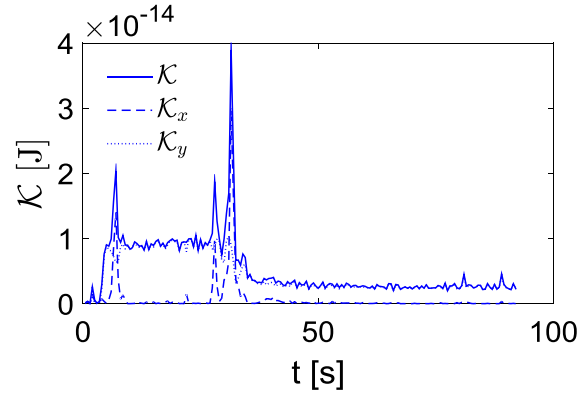

(b) QS kinetic energy

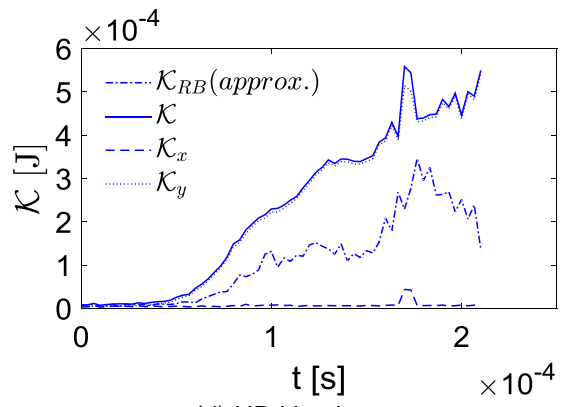

(d) HR kinetic energy

Figure 16: Example of strain and kinetic energy terms for QS (a, b) and HR (c, d) loading (specimen type A).

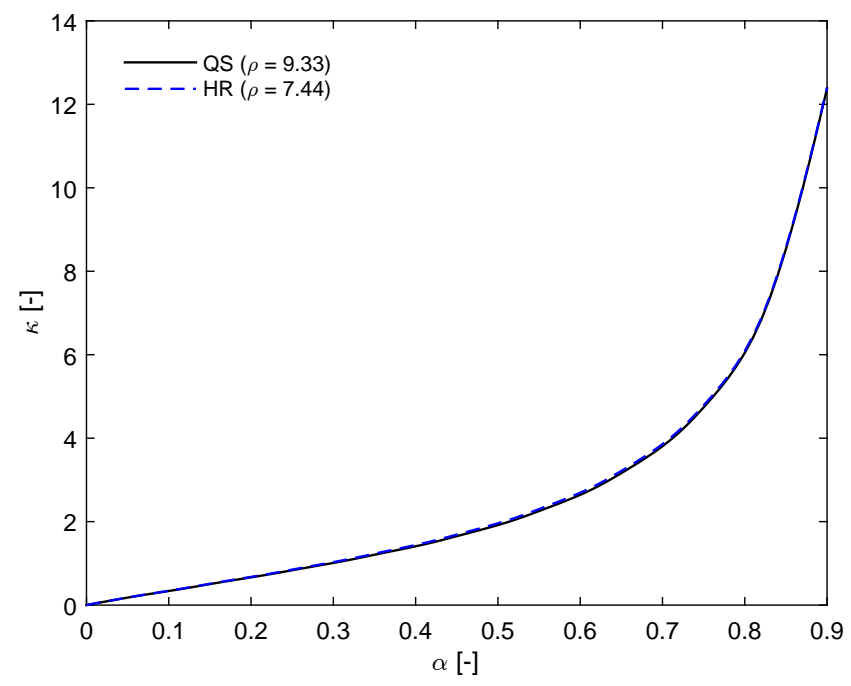

Figure 17: Correction function $\kappa$ vs. shape parameter $\alpha$ for QS and HR loading. 

value of the fracture toughness $R_{s s}$ and the length of the fracture process zone $l_{f p z}$ are also listed in Table 5, where $\kappa_{0}=\left.\kappa\right|_{\alpha=\alpha_{0}}, f_{0}=\left.\sqrt{\kappa}\right|_{\alpha=\alpha_{0}}$ and $f_{0}=$ $\partial \sqrt{\kappa} /\left.\partial \alpha\right|_{\alpha=\alpha_{0}}$. As the fitting approaches weigh the data points in various ways, the results may slightly differ [41.

Table 5: Size effect law fits 41.

\begin{tabular}{lllll}
\hline Regression fit & Formula & Fitting parameters & $R_{s s}$ & $l_{f p z}$ \\
\hline Linear regression I & $\frac{1}{\sigma_{u}^{2}}=m w+q$ & $\mathrm{~m}, \mathrm{q}$ & $\frac{\kappa_{0}}{E} \frac{1}{m}$ & $\frac{f_{0}}{2 f_{0}} \frac{q}{m}$ \\
Linear regression II & $\frac{1}{w \sigma_{u}^{2}}=\dot{m} \frac{1}{w}+\dot{q}$ & $\dot{m}, \dot{q}$ & $\frac{\kappa_{0}}{E} \frac{1}{\dot{q}}$ & $\frac{f_{0}}{2 f_{0}} \frac{\dot{m}}{\dot{q}}$ \\
Bilogarithmic & $\ln \left(\sigma_{u}\right)=\ln \left(\frac{M}{\sqrt{Q+w}}\right)$ & $\mathrm{M}, \mathrm{Q}$ & $\frac{\kappa_{0}}{E} M^{2}$ & $\frac{f_{0}}{2 f_{0}} Q$ \\
\hline
\end{tabular}

Fig. 18 shows the experimental data and the best fitting curves for each of the three recommended regression approaches. The corresponding curve fitting parameters and the respective coefficient of determination $R^{2}$ are summarized in Table 6. While the QS data points are approximated very well by all of the regression approaches, the highest coefficient of determination for the HR data is found by using linear regression II.

Knowing the size effect laws, the tensile R-curve of the laminate, $R$, can be calculated by using the previously described analysis scheme (see section 2). Finally, the R-curve of the $0^{\circ}$ plies, $R_{0}$, is obtained by applying Eq. 14. In Fig. 19 . the $R_{0}$-curves for each regression approach and for both investigated strain rate regimes are plotted. Regardless of the regression fit, the tensile intralaminar fracture toughness of the $0^{\circ}$ plies under HR loading is larger than that obtained under QS conditions. The values calculated for $R_{s s}^{0}$ and $l_{f p z}$ are summarized in Table 7 The steady-state values of the fracture toughness of the $0^{\circ}$ plies, $R_{s s}^{0}$, under QS loading is in the same order as measured with the same analysis 420 scheme by Catalanotti et al. [1], who reported a value of $R_{s s}^{0}=205 \mathrm{~kJ} / \mathrm{m}^{2}$. In contrast to the presented work, larger specimens, directly fixed in the clamping 


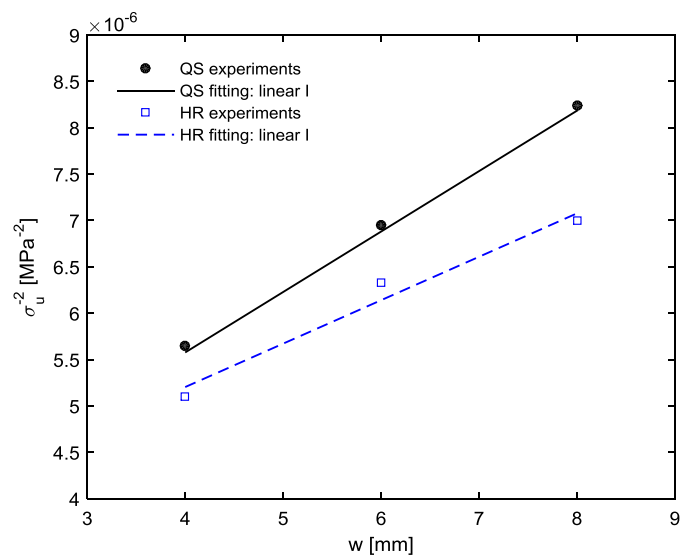

(a) linear regression I

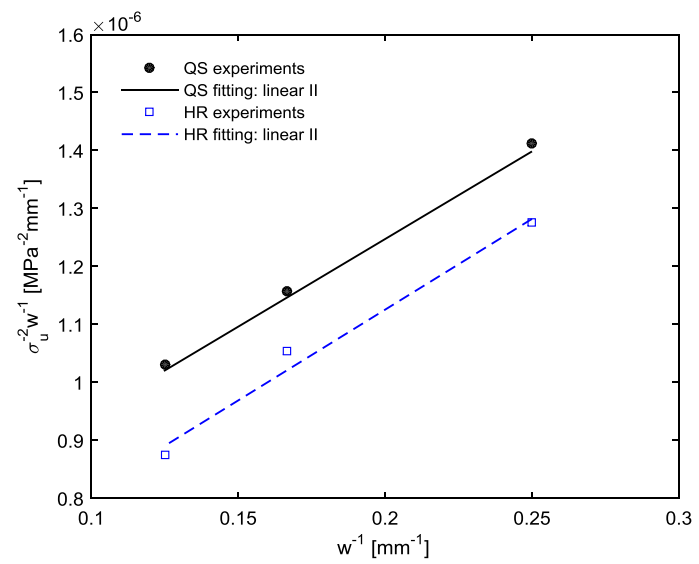

(b) linear regression II

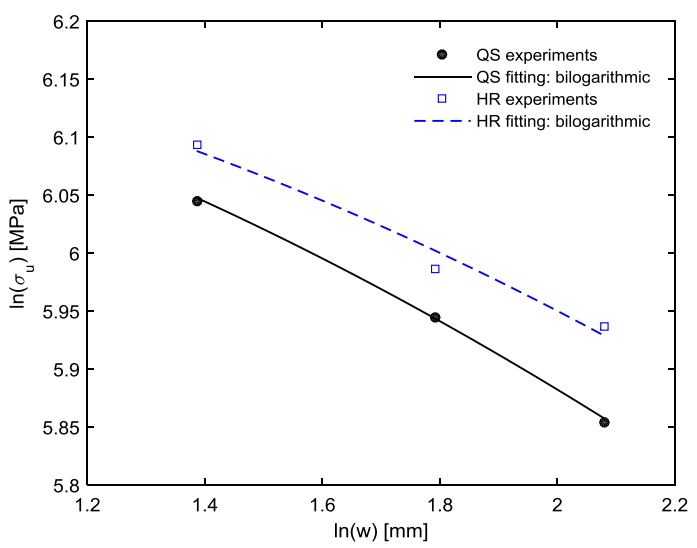

(c) bilogarithmic

Figure 18: Experimental data and best fitting curves for linear regression I (a), linear regression II (b) and bilogarithmic regression (c) forg $8 \mathrm{~S}$ and HR loading. 
Table 6: Regression fitting parameters.

\begin{tabular}{llll}
\hline Regression fit & Parameter & QS & HR \\
\hline Linear regression I & $\mathrm{m}\left[\mathrm{MPa}^{-2} \mathrm{~mm}^{-1}\right]$ & $6.52 \times 10^{-7}$ & $4.68 \times 10^{-7}$ \\
& $\mathrm{q}\left[\mathrm{MPa}^{-2}\right]$ & $2.97 \times 10^{-6}$ & $3.31 \times 10^{-6}$ \\
& $\mathrm{R}^{2}[-]$ & 0.999 & 0.969 \\
\hline Linear regression II & $\dot{m}\left[\mathrm{MPa}^{-2}\right]$ & $3.02 \times 10^{-6}$ & $3.13 \times 10^{-6}$ \\
& $\dot{q}\left[\mathrm{MPa}^{-2} \mathrm{~mm}^{-1}\right]$ & $6.43 \times 10^{-7}$ & $4.99 \times 10^{-7}$ \\
& $\mathrm{R}^{2}[-]$ & 0.998 & 0.982 \\
\hline Bilogarithmic & $\mathrm{M}[\mathrm{MPa} \sqrt{m m}]$ & 1,244 & 1,439 \\
& $\mathrm{~N}[\mathrm{~mm}]$ & 4.64 & 6.67 \\
& $\mathrm{R}^{2}[-]$ & 0.999 & 0.972 \\
\hline
\end{tabular}

jaws of the testing machines, were used in 1]. The similarity of the results therefore underlines that the modified specimen configuration, adapted to the SHTB-setup, is well suited and is furthermore a sign for the robustness of the method. $R_{s s}^{0}$ for IM7-8552 was also determined using compact tension specimens by Catalanotti et al. 14] and Laffan et al. [58, who documented values of $R_{s s}^{0}=133.3 \mathrm{~kJ} / \mathrm{m}^{2}$ and $R_{s s}^{0}=147.2 \mathrm{~kJ} / \mathrm{m}^{2}$, respectively. As for $R_{s s}^{0}$, a strain rate effect is found for the fracture process zone $l_{f p z}$ in the presented work. Strongly differing values are reported in literature for $l_{f p z}(\approx 1.5 \mathrm{~mm}$ [58], $2.63 \mathrm{~mm}$ [1], $3.4 \mathrm{~mm}$ [14]. The obtained QS value in the order of $1.4 \mathrm{~mm}$ therefore seems to have a plausible magnitude.

To simplify the use of the measured R-curves in Finite Fracture Mechanics models, Bažant and Planas [41] suggest to express them in an analytical form by using the following equation:

$$
\begin{cases}R_{0}=R_{s s}\left[1-(1-\beta \Delta a)^{n}\right] & \text { if } \Delta a<l_{f p z} \\ R_{0}=R_{s s} & \text { if } \Delta a \geq l_{f p z}\end{cases}
$$

${ }_{435}$ in which $\beta$ and $n$ are the parameters that best fit the formula to the R-curve. The optimal parameters for both investigated strain rate regimes are listed in 


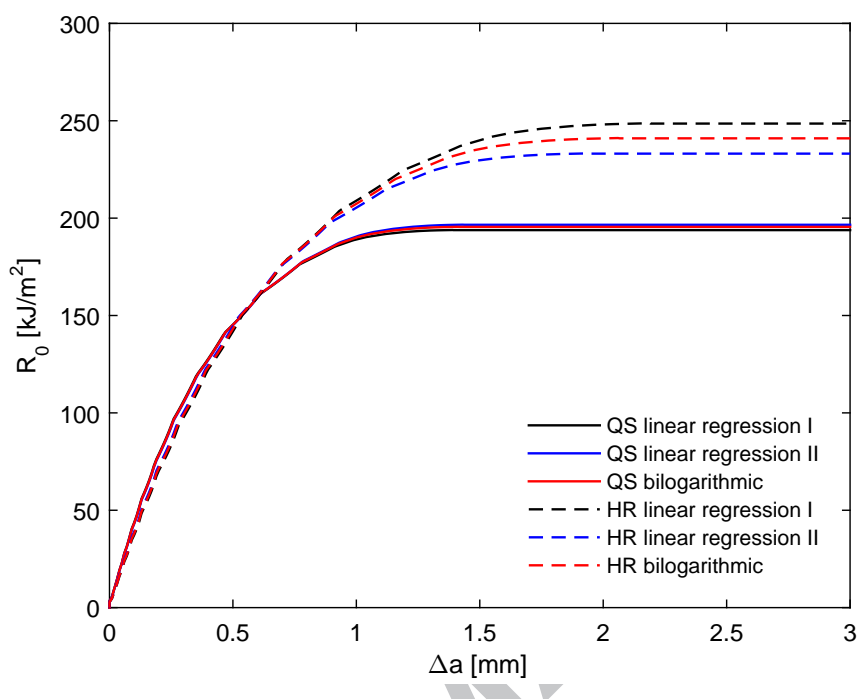

Figure 19: Tensile R-curves of IM7-8552 of each regression approach for QS and HR loading.

Table 7: Summary of the fracture toughness properties.

\begin{tabular}{llll}
\hline Regression fit & Property & QS & HR \\
\hline Linear regression I & $R_{s s}^{0}\left[\mathrm{~kJ} / \mathrm{m}^{2}\right]$ & 193.8 & 248.6 \\
& $l_{f p z}[\mathrm{~mm}]$ & 1.39 & 2.21 \\
\hline Linear regression II & $R_{s s}^{0}\left[\mathrm{~kJ} / \mathrm{m}^{2}\right]$ & 196.6 & 233.1 \\
& $l_{f p z}[\mathrm{~mm}]$ & 1.44 & 1.94 \\
\hline Bilogarithmic & $R_{s s}^{0}\left[\mathrm{~kJ} / \mathrm{m}^{2}\right]$ & 195.5 & 241.0 \\
& $l_{f p z}[\mathrm{~mm}]$ & 1.42 & 2.07 \\
\hline
\end{tabular}


Table 8

Table 8: Fitting parameters of the analytical R-curve.

\begin{tabular}{llll}
\hline Regression fit & Fitting parameter & QS & HR \\
\hline Linear regression I & $\beta\left[\mathrm{mm}^{-1}\right]$ & 0.5358 & 0.3383 \\
& $\mathrm{n}[-]$ & 4.511 & 4.552 \\
\hline Linear regression II & $\beta\left[\mathrm{mm}^{-1}\right]$ & 0.5192 & 0.3814 \\
& $\mathrm{n}[-]$ & 4.509 & 4.550 \\
\hline Bilogarithmic & $\beta\left[\mathrm{mm}^{-1}\right]$ & 0.5260 & 0.3587 \\
& $\mathrm{n}[-]$ & 4.510 & 4.551 \\
\hline
\end{tabular}




\section{Conclusions}

The results of the presented work show, that the size effect method can not only be used to measure the R-curve for fiber tensile failure mode under quasi-static, but also under high rate loading conditions. The modified DENT specimen configuration, adapted to the SHTB-setup, is well suitable for dynamic tests on a split-Hopkinson tension bar. The desired mode I loading condition appears at both investigated strain rate regimes, which can be verified by the axial and shear strain field distributions obtained from digital image correlation. Furthermore, the quasi-static steady-state fracture toughness, obtained within this work, correlates well with the value determined by Catalanotti et al. [1], who tested significantly larger specimens without using endcaps.

The nearly constant strain rate and the comparison of the strain energy and kinetic energy terms, all calculated on basis of the available DIC data, indicate that the use of the quasi-static fracture theory is applicable for the data reduction of the SHTB tests. The stress equilibrium condition, following classic SHPBA, could not be shown initially, as the the incident- and reflectedpulse can not fully be measured without signal superposition at the incident-bar strain gauge of the used setup. However, the correction method proposed in this work, using a measured strain pulse from a separate BT test, enables a good estimation of the stress equilibrium. The equilibrium checks carried out with the non-overlapping pulse indicate, that the used DENT-specimens are in dynamic stress equilibrium well before ultimate failure occurs.

${ }_{460}$ The calculated R-curves for fiber tensile failure show, that the steady-state value of the fracture toughness and the length of the fracture process zone increases with increasing strain rate, therefore exhibiting the same tendency as found for the fiber compressive failure mode [38. Along with experimental data presented in [38, 51, 54, 59, 60], the results obtained in the present study complete a comprehensive dynamic material data set for the carbon-epoxy material IM7-8552, which may be used for simulations of dynamic load scenarios and the further development of composite material models. 


\section{Acknowledgements}

The authors would like to acknowledge Dr. Iman Taha and Christina Aust from Fraunhofer Institution for Casting, Composite and Processing Technology (IGCV) for providing the Photron FASTCAM SA-Z high speed camera. The presented research did not receive a specific grant from funding agencies in the public, commercial, or not-for-profit sectors.

\section{Appendix A. Stress-strain curves}

The stress-strain curves of the specimen sizes A, B and C are shown in Fig. A.1, Fig. A.2 and Fig. A.3, respectively.

(a)

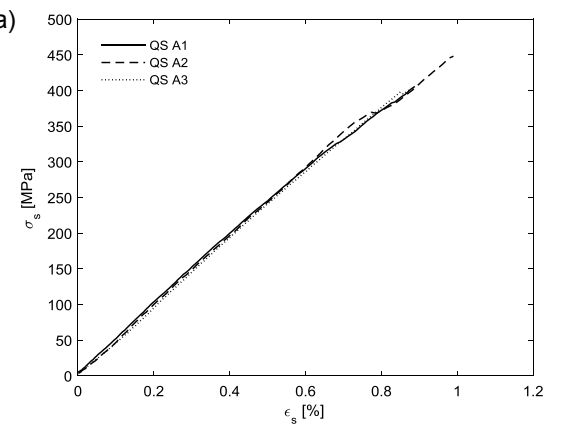

(b)

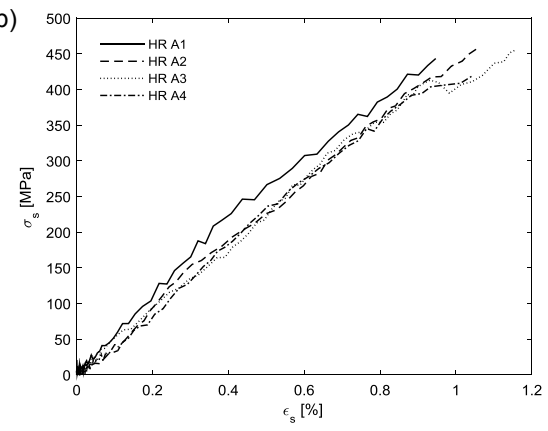

Figure A.1: Stress-strain responses of specimen size A for QS (a) and HR (b) loading.

(a)

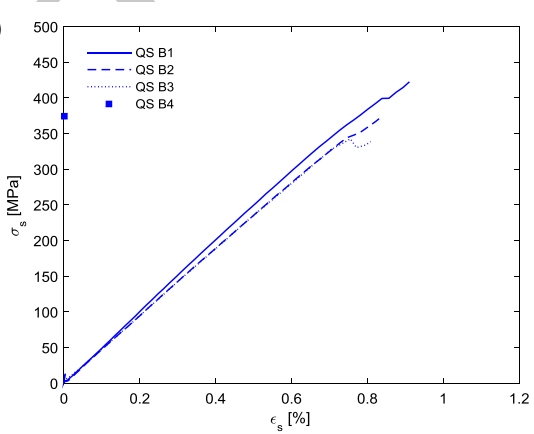

(b)

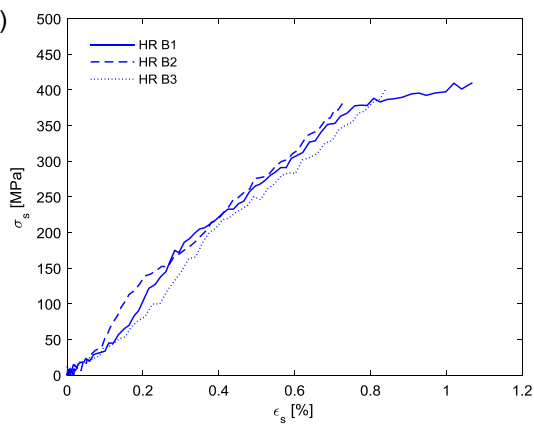

Figure A.2: Stress-strain responses of specimen size B for QS (a) and HR (b) loading. 
(a)

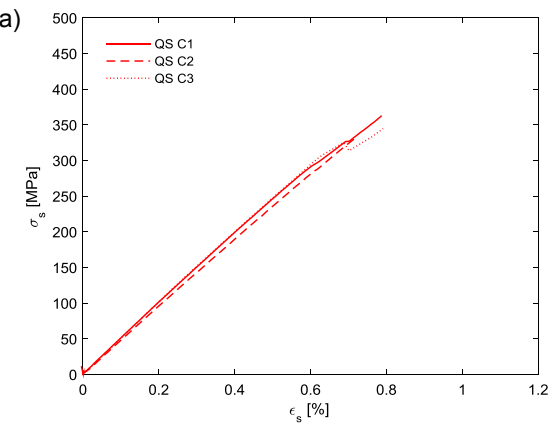

(b)

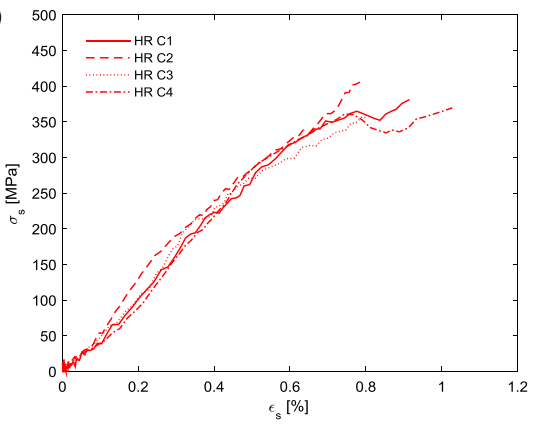

Figure A.3: Stress-strain responses of specimen size C for QS (a) and HR (b) loading.

\section{References}

[1] Catalanotti G, Arteiro A, Hayati M, Camanho PP. Determination of the mode I crack resistance curve of polymer composites using the sizeeffect law. Engineering Fracture Mechanics 2014;118:49-65. doi 10.1016/ j.engfracmech.2013.10.021.

[2] Tay TE, Tan SHN, Tan VBC, Gosse JH. Damage progression by the element-failure method (EFM) and strain invariant failure theory (SIFT). Composites Science and Technology 2005;65:935-944.

[3] Pinho ST, Iannucci L, Robinson P. Physically based failure models and criteria for laminated fibre-reinforced composites with emphasis on fibre kinking. part ii: Fe implementation. Composites: Part A 2006;37:766-777.

[4] Lapczyk I, Hurtado JA. Progressive damage modeling in fiber-reinforced materials. Composites: Part A 2007;38:2333-2341. doi $10.1016 / j$. compositesa.2007.01.017.

[5] van der Meer FP, Oliver C, Sluys LJ. Computational analysis of progressive failure in a notched laminate including shear nonlinearity and fiber failure. Composite Science and Technology 2010;70:692-700.

[6] Abisset E, Daghia F, Ladevèze P. On the validation of a damage mesomodel 
for laminated composites by means of open-hole tensile tests on quasiisotropic laminates. Composites: Part A 2011;42:1515-1524.

[7] Falzon BG, Apruzzese P. Numerical analysis of intralaminar failure mechanisms in composite structures. Part I: FE implementation. Composite Structures 2011;93:1039-1046.

[8] Iarve EV, Gurvich MR, Mollenhauer DH, Rose CA, Dávila CG. Meshindependent matrix cracking and delamination modeling in laminated composites. International Journal for Numerical Methods in Engineering 2011;88:749-773.

[9] Camanho PP, Ercin GH, Catalanotti G, Mahdi S, Linde P. A finite fracture mechanics model for the prediction of the open-hole strength of composite laminates. Composites: Part A 2012;43:1219-1225. doi:10.1016/j. compositesa.2012.03.004.

[10] Dávila CG, Rose CA, Camanho PP. A procedure for superimposing linear cohesive laws to represent multiple damage mechanisms in the fracture of composites. International Journal of Fracture 2009;158:211-223. doi 10 . $1007 /$ s10704-009-9366-z.

[11] ASTM E399-90, Standard test method for plane-strain fracture toughness of metallic materials, ASTM International, West Conshohocken, PA. 1993.

[12] ASTM E561-910, Standard Test Method for K-R Curve Determination, ASTM International, West Conshohocken, PA. 2010.

[13] Pinho ST, Robinson P, Iannucci L. Fracture toughness of the tensile and compressive fibre failure modes in laminated composites. Composites Science and Technology 2006;66:2069-2079. doi 10.1016/j.compscitech. 2005.12 .023

[14] Catalanotti G, Camanho PP, Xavier J, Dávila CG, Marques AT. Measurement of resistance curves in the longitudinal failure of composites using dig- 
ital image correlation. Composites Science and Technology 2010;70:19861993. doi $10.1016 / j$. compscitech.2010.07.022.

[15] Zobeiry N, Vaziri R, Poursartip A. Characterization of strain-softening behavior and failure mechanisms of composites under tension and compression. Composites: Part A 2015;68:29-41. doi 110.1016/S0020-7683(03) 00016-7

[16] Laffan MJ, Pinho ST, Robinson P, Iannucci L. Measurement of the in situ ply fracture toughness associated with mode I fibre tensile failure in FRP. Part I: Data reduction. Composites Science and Technology 2010;70:606613. doi $10.1016 / j$. compscitech.2009.12.016

[17] Laffan MJ, Pinho ST, Robinson P, Iannucci L. Measurement of the in situ ply fracture toughness associated with mode I fibre tensile failure in FRP. Part II: Size and lay-up effects. Composites Science and Technology 2010;70:614-621. doi 10.1016/j.compscitech.2009.12.011.

[18] Blanco N, Trias D, Pinho ST, Robinson P. Intralaminar fracture toughness characterisation of woven composite laminates. Part II: Experimental characterisation. Engineering Fracture Mechanics 2014;131:361-370.

[19] Bergan A, Dávila C, Leone F, Awerbuch J, Tan TM. A Mode I cohesive law characterization procedure for through-the-thickness crack propagation in composite laminates. Composites Part B 2016;94:338-349.

[20] Yeow YT, Morris DH, Brinson HF. A correlative study between analysis and experiment on the fracture behavior of graphite/epoxy composites. Journal of Testing and Evaluation 1979;7:117-125.

545 [21] Harris CE, Morris DH. Fracture behaviour of thick, laminated graphite/epoxy composites. Tech. Rep. Contractor Report 3784; NASA, USA; 1984.

[22] Harris CE, Morris DH. A comparison of the fracture behaviour of thick laminated composites utilizing compact tension, three-point bend, and 
center-cracked tension specimens. Fracture Mechanics, ASTM STP 905 $1995 ; 17: 124-135$.

[23] Underwood JH, Burch IA, Bandyopadyay S. Effects of notch geometry and moisture on fracture strength of carbon/epoxy and carbon/bismaleimide laminates. Composite Materials, ASTM STP 1110 1991;3:667-685.

[24] Vaidya RS, Sun CT. Fracture criterion for notched thin composite laminates. AIAA Journal 1997;35:311-316.

[25] Masters JE. Translaminar fracture toughness of a composite wing skin made of stitched warp-knit fabric. NASA/CR-201728. Tech. Rep.; 1997.

[26] Erçin GH, Camanho PP, Xavier J, Catalanotti G, Mahdi S, Linde P. Size effects on the tensile and compressive failure of notched composite laminates. Composite Structures 2013;96:736-744.

[27] Donadon MV, Falzon BG, Iannucci L, Hodgkinson JM. Intralaminar toughness characterisation of unbalanced hybrid plain weave laminates. Composites: Part A 2007;38:15971611.

[28] Hansen U, Jr. JWG. Dependence of intralaminar fracture toughness on direction of crack propagation in unidirectional composites. Journal of Composite Technology \& Research 1998;20:89-99.

[29] Hallett SR, Wisnom MR. Experimental investigation of progressive damage and the effect of layup in notched tensile tests. Journal of Composite Materials 2006;40:119-141.

[30] Arteiro A, Catalanotti G, Xavier J, Camanho PP. Large damage capability of non-crimp fabric thin-ply laminates. Composites: Part A 2014;63:110122.

[31] Erçin GH. Stress gradient effects in laminated composites. Ph.D. thesis; University of Porto; 2013. 
[32] Catalanotti G, Xavier J, Camanho PP. Measurement of the compressive crack resistance curve of composites using the size effect law. Composites: Part A 2014;56:300-307. doi $10.1016 /$ j.compositesa.2013.10.017.

[33] Catalanotti G, Xavier J. Measurement of the mode II intralaminar fracture toughness and R-curve of polymer composites using a modified Iosipescu specimen and the size effect law. Engineering Fracture Mechanics 2015;138:202-214. doi $10.1016 /$ j.engfracmech.2015.03.005.

[34] Pinto RF, Catalanotti G, Camanho PP. Measuring the intralaminar crack resistance curve of fibre reinforced composites at extreme temperatures. Composites: Part A 2016;91:145-155. doi 10.1016/j.compositesa.2016. 10.004

[35] Sierakowski RL. Strain rate effects in composites. Applied Mechanics Reviews 1997;50:741-761. doi 10.1115/1.3101860.

[36] Jacob GC, Starbuck JM, Fellers JF, Simunovic S, Boeman RG. Strain rate effects on the mechanical properties of polymer composite materials.

a Journal of Applied Polymer Science 2004;94:296-301. doi 10.1002/app. 20901

[37] Jacob GC, Starbuck JM, Fellers JF, Simunovic S, Boeman RG. The effect of loading rate on the fracture toughness of fiber reinforced polymer composites. Journal of Applied Polymer Science 2005;96:899-904. doi:10.1002/app.21535.

[38] Kuhn P, Catalanotti G, Xavier J, Camanho P, Koerber H. Fracture toughness and crack resistance curves for fiber compressive failure mode in polymer composites under high rate loading. Composite Structures 2017;182:164-175. doi 10.1016/j. compstruct. 2017.09.040.

[39] Jiang F, Vecchio KS. Hopkinson bar loaded fracture experimental technique: A critical review of dynamic fracture toughness tests. Applied Mechanics Reviews 2009;62:1-39. doi 10.1115/1.3124647. 
[40] Leite BM, Leite LFM, Reis VL, Donadon MV, da Silveira NNA. Strain rate effects on the intralaminar fracture toughness of composite laminates subjected to compressive load. Composite Structures 2018;186:94-105. doi $10.1016 / j$. compstruct.2017.11.091.

[41] Bažant ZP, Planas J. Fracture and size effect in concrete and other quasibrittle materials. CRC Press LLC, Boca Raton, Florida, USA; 1998.

[42] Beguelin P, Fond C, Kausch HH. The influence of inertial effects on the fracture of rapidly loaded compact tension specimens Part A: loading and fracture initiation. International Journal of Fracture 1998;89:85-102.

[43] Suo Z, Bao G, Fan B, Wang TC. Orthotropy rescaling and implications for fracture in composites. International Journal of Solids and Structures $1990 ; 28: 235-248$.

[44] Laffan MJ, Pinho ST, Robinson P, McMillan AJ. Translaminar fracture toughness testing of composites: a review. Polymer Testing 2012;31:481489. doi $10.1016 / \mathrm{j} \cdot$ polymertesting.2012.01.002.

[45] Bao G, Ho S, Suo Z, Fan B. The role of material orthotropy in fracture specimens for composites. International Journal of Solids and Structures 1992;29:1105-1116.

[46] Krueger R. The virtual crack closure technique: History, approach and applications. NASA/CR-2002-211628. Tech. Rep. ICASE Report No. 200210; ICASE, Hampton, Virginia, USA; 2002.

[47] Dassault Systèms. Abaqus Version 6.14-2 Documentation. 2014.

[48] Harding J, Welsh LM. A tensile testing technique for fiber-reinforced composites at impact rates of strain. Journal of Materials Science 1983;18:18101826.

[49] Zhou Y, Wang Y, Jeelani S, Xia Y. Experimental study on tensile behavior of carbon fiber and carbon fiber reinforced aluminum at different 
strain rate. Applied Composite Materials 2007;14:17-31. doi 10.1007/ s10443-006-9028-5.

[50] Taniguchi N, Nishiwaki T, Kawada H. Tensile strength of unidirectional CFRP laminate under high strain rate. Advanced composite materials 2007;16:167-180.

[51] Koerber H, Xavier J, Camanho PP. High strain rate characterisation of unidirectional carbon-epoxy IM7-8552 in transverse compression and in-plane shear using digital image correlation. Mechanics of Materials 2010;42:10041019. doi $10.1016 /$ j.mechmat.2010.09.003.

[52] S. Nemat-Nasser . Introduction to high strain rate testing. In: ASM handbook mechanical testing and evaluation; vol. 8. ASM International Ohio USA; 2000.

[53] Gerlach R, Kettenbeil C, Petrinic N. A new split Hopkinson tensile bar design. International Journal of Impact Engineering 2012;50:63-67. doi 10 . 1016/j.ijimpeng.2012.08.004.

[54] Koerber H, Camanho PP. High strain rate characterisation of unidirectional carbon-epoxy IM7-8552 in longitudinal compression. Composites Part A 2011;42:462-470. doi $10.1016 /$ j.compositesa.2011.01.002.

[55] Nemat-Nasser S, Isaacs JB, Starrett JE. Hopkinson techniques for dynamic recovery experiments. Proceedings: Mathematical and Physical Sciences 1991;435:371-391.

[56] Kolsky H. An investigation of the mechanical properties of materials at very high rates of loading. Proc Phys Soc London 1949;Sect. B. 62 (IIB):676-700.

655

[57] G. T. Gray III . Classic split-Hopkinson pressure bar testing. In: ASM handbook mechanical testing and evaluation; vol. 8. ASM International Ohio USA; 2000, pp. 462-476. 
[58] Laffan MJ, Pinho ST, Robinson P, McMillan AJ. Translaminar fracture toughness: The critical notch tip radius of $0^{\circ}$ plies in CFRP. Composites Science and Technology 2011;72:97-102.

[59] Koerber H, Kuhn P, Ploeckl M, Otero F, Gerbaud PW, Rolfes R, et al. Constitutive modelling and experimental characterization of the nonlinear stress-strain behaviour of unidirectional carbon-epoxy under high strain rates. Advanced Modelling and Simulation in Engineering Sciences $2018 ; 5: 1-24$.

[60] Ploeckl M, Kuhn P, Grosser J, Wolfahrt M, Koerber H. A dynamic test methodology for analyzing the strain-rate effect on the longitudinal compressive behavior of fiber-reinforced composites. Composite Structures 2017;180:429-438. doi $10.1016 /$ j.compstruct. 2017.08.048. 